\title{
RETROFITTING ANALYSIS OF TANKER SHIP HULL STRUCTURE SUBJECTED TO CORROSION
}

UDC 621.78.019.84: 004.413.4: 629.5.018.4

Original scientific paper

\begin{abstract}
Summary
The objective of the study presented here is to investigate the efficiency in recovering the structural capacity of a double bottom side girder plate of an oil tanker, accounting for the probability of failure and cost associated with the retrofit or substitution of the plate. The side girder includes a manhole shape opening, and it is subjected to a uniaxial compressive load and random non-uniform corrosion degradation. The Monte Carlo simulator models the nonuniformity of the corrosion degradation. Four cases are considered for the retrofitting process: the replacement of the entire plate, reinforcement by two longitudinal stiffeners, two longitudinal and two transversal stiffeners, a flange on the opening. Twelve scenarios are selected and analysed. Four strategies of accessing the space where the side girder is located to perform the retrofit and replacement are considered: no opening, access from the deck of the vessel, access from the side of the vessel, access from the bottom of the vessel. The First Order Reliability Method is used to estimate the reliability of the different solutions towards time. The cost and associated risk assessment are performed to compare the scenarios and determine the most convenient one. A comparison of the most advantageous solutions and the worst one is conducted considering the probability of failure, cost and associated risk.
\end{abstract}

\section{Keywords: $\quad$ Corrosion; Ultimate Strength, Retrofitting, Cost-Benefit, Risk}

\section{Introduction}

Marine structures operate in a harsh environment and are subjected to degradation during their service life. This deterioration leads to two main aspects of the maritime industry: safety and costs. On one side, Classification Societies Rules [1] indicate necessary parameters to assure the safety of a vessel under the structural point of view such as maximum corrosion wastage allowed, minimum sectional moduli, etc., on the other side the different subject involved in the industry tries to contain the cost associated with safety.

The classical theory of system maintenance describes the failure of components by probabilistic models, often Weibull family, which represents failure rates in operational phases and the ageing phases of the life of components as described in various textbooks, such as in [2-4].

Probabilistic models to describe failure components and demonstrated their application to structural maintenance of ships that are subjected to corrosion and fatigue damage have been 
presented in [5-9] used and work presented in [10-12] proposed the planning of structural maintenance of ships based on structural reliability approaches and the concept of Bayesian analysis to the inspection procedure is applied in [13].

Fujita, et al. [14] proposed an adaptive strategy for inspection and repair where the inspection time and the decision criteria for repair can be optimised concerning the total cost and Lotsberg and Kirkemo [15] proposed a method based on probabilistic analysis combined with a resource allocation technique.

Fujimoto and Swilem [16] created a model to find the optimal inspection strategy to minimise the expected costs of inspections employing a Markov Chain Model to describe the entire probabilistic structure of the deterioration process and Madsen [17] applied stochastic models to the study of fatigue crack propagation and inspections.

Faber, et al. [18] presented a simplified inspection and maintenance planning analysis for a tubular joint in a jacket type offshore structure, and Garbatov and Soares $[6,19]$ applied probabilistic models related to degradation to study risk-based maintenance decisions, and an analysis of the reliability of a bulk carrier hull subjected to the degrading effect of corrosion was presented in [20]

The introduction of risk analysis into the traditional design process cost-effectively established safety objectives. Papanikolaou, et al. [21] proposed risk as a measure of the safety level for the optimisation of the design and Skjong, et al. [22] formalised risk assessment methodology in the design process proposing risk as a design objective among conventional ones, Guia, et al. [23] studied a cost associated with the optimum structural safety level and a risk-based framework for ship and structural design accounting for maintenance planning in [24].

Nowadays the typical procedure is the substitution of the deteriorated plate with a new one. However, Classification Societies permit a different approach under the mandatory occurrence that structural safety is achieved. A new solution to this problem is the retrofitting of the plate.

Caridis [25] demonstrated the costs associated with the structure renewal or reinforcement and a risk-based framework for the ship and structural design accounting for maintenance planning was proposed in [24, 26, 27].

Chichi and Garbatov [28] studied the regain of the ultimate strength of a non-uniform corroded plate with manhole opening under uniaxial load with the retrofitting process.

In this study is presented a model that relates the retrofitting process or substitution of the plate with risk and cost associated. The philosophy behind the analysis is to furnish to subjects of the maritime industry a tool to quantify the risk for the solution proposed.

Plates are the principal structural components in marine structures. In literature are present studies on the assessment of the ultimate strength of steel plates. Several studies have been performed on the ultimate strength of plates and stiffened plates with an opening.

Shanmugam, et al. [29] studied the variation of ultimate strength in thin perforated plates and the incidence of the different positioning of the opening affecting the ultimate strength. They also analysed the post-buckling behaviour and the ultimate strength of perforated plates under uniaxial or biaxial compression.

Paik, et al. [30] developed formulae for the assessment of plates under the combination of the biaxial compression and edge shear and Kim, et al. [31] proposed a formula for the assessment of the ultimate strength of a perforated plate under axial compression. This study was improved in [32] with experiments, both numerically and in scale, of perforated plates. In this study, it has been proved the influence of different kind of stiffeners on the ultimate strength.

To investigate experimentally and numerically the severe non-uniform corrosion Garbatov, et al. [33] studied the degradation effect on the load carrying capacity of stiffened plates, where different factors leading to a reduction of structural capacity have been investigated, including 
the material properties, the degree of degradation, equivalent thickness and testing support conditions.

The influence of large openings on side shell plating demonstrating that the relation between the increase in the number of holes and the diminution of the ultimate strength bending capacity is not linear was analysed in [34-37].

The objective of the study here is to analyse the possibility to recover the strength of the side girder plate of an oil tanker with a retrofit or substitution of the plate. The panel presents a manhole shape opening, and it is subjected to uniaxial compressive load and randomised nonuniform corrosion. For the evaluation of results, a risk assessment is performed, and also a comparison between the most advantageous and the worst solutions is conducted considering the probability of failure and cost.

\section{Strength assessment}

In the past several corrosion deterioration models, linear and non-linear have been developed. The present study adopts the corrosion deterioration model developed in [38], which was latterly calibrated in [20] and used to develop a formulation in [39] that address the limited corrosion depth measurement data and the current Common Structural Rules [1], CSR corrosion adds in defining the corrosion degradation depth on both sides of a steel plate.

The non-linear corrosion degradation model developed in [20,39] classify the ship hull plates according to their surrounding environments considering the boundaries between any two spaces that can have similar or different environments and in consequence different corrosion wastage. The thickness reduction due corrosion of any ship plate is equal to the sum of the corrosion wastage on each side [39]:

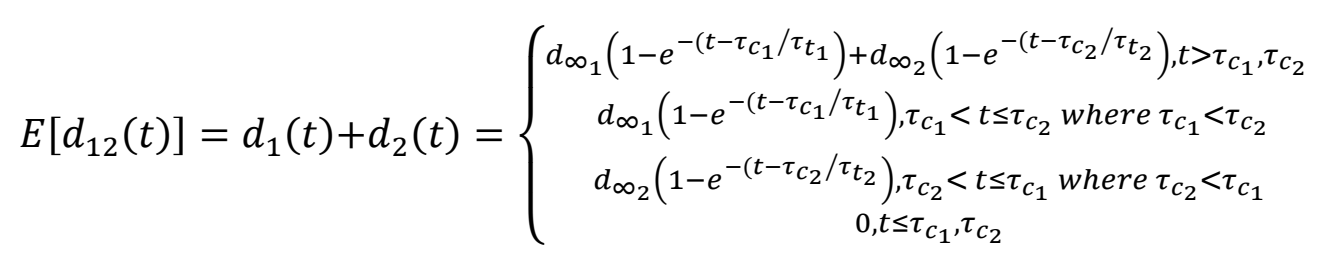

where $\mathrm{E}\left[d_{12}(t)\right]$ is the corrosion wastage of both sides of the plate, $d_{1}(t)$ is the corrosion wastage of the side $1, d_{2}(t)$ is the corrosion wastage of the side $2, t$ is the time, $d_{\infty_{1}}$ and $d_{\infty_{2}}$ are the long-term corrosion wastage of the two sides, $\tau_{c_{1}}$ and $\tau_{c_{2}}$ are the coating life of the two sides, $\tau_{t_{1}}$ and $\tau_{t_{2}}$ are the transition time of the two sides.

The corrosion depth is assumed to be described by the Log-Normal distribution with a mean value of $E\left[d_{12}(t)\right]$ and standard deviation as derived in [20]:

$$
\operatorname{StDev}\left[d_{12}(t)\right]=\left\{\begin{array}{r}
0, t \leq \tau_{c_{1}}, \tau_{c_{2}} \\
a_{12} * \log \left(t-\bar{\tau}_{c}-b_{12}\right)-c_{12}, t \geq \tau_{c_{1}}, \tau_{c_{2}}
\end{array}\right.
$$

where $\bar{\tau}_{c}$ is the minimum coating life between the two sides of the plate, $a_{12}, b_{12}$ and $c_{12}$ are respectively equal to 13.84 years, -9.16 years and 13.22 years.

The procedure developed in [28] is followed to identify the non-uniform corrosion degradation of plates employing the Monte Carlo [40] approach.

The structure analysed here is considered to be a side-girder in the double bottom of an oil tanker. The structure has the following main characteristics: length, $l=4000 \mathrm{~mm}$, width, $b=1400$ $\mathrm{mm}$, initial thickness, $t_{p, \text { initial }}=22 \mathrm{~mm}$. The structure is represented by a plate with a manhole 
type opening with an extended elliptical opening, $b_{\text {opening }}=600 \mathrm{~mm}$, length of opening, $l_{\text {opening }}=800 \mathrm{~mm}$, and the radius of the opening, $r_{\text {opening }}=300 \mathrm{~mm}$, as shown in Pogreška! Izvor reference nije pronađen..

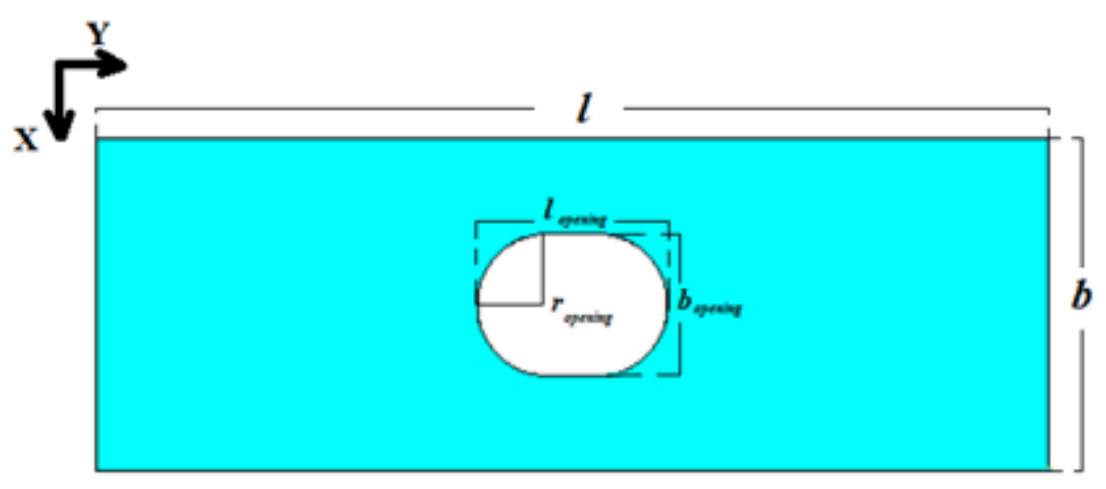

Fig. 1 - Geometry of the plate studied.

The elastic modulus, $E$ is $205.8 \mathrm{GPa}$, yield stress and the Poisson coefficient are $\sigma_{\mathrm{y}}=355$ $\mathrm{MPa}$ and $\mathrm{v}=0.3$ respectively. The plate is subjected to a uniaxial load applied in the direction of the Y-axis. The boundary conditions adopted in the non-linear FE analysis are shown in Table 1 .

Table 1 - Boundary conditions adopted in the study

\begin{tabular}{|c|c|c|c|c|}
\cline { 2 - 5 } \multicolumn{1}{c|}{} & $\boldsymbol{U}_{\boldsymbol{x}}$ & $\boldsymbol{U}_{\boldsymbol{y}}$ & $\boldsymbol{U}_{z}$ & $\boldsymbol{R o t}_{\boldsymbol{x}}$ \\
\hline $\boldsymbol{y}=\mathbf{0}$ & Free & Constrained & Constrained & Constrained \\
\hline $\boldsymbol{y}=\boldsymbol{L}$ & Free & Free & Constrained & Constrained \\
\hline $\boldsymbol{x}=\mathbf{0}$ & Free & Free & Constrained & Free \\
\hline $\boldsymbol{x}=\boldsymbol{b}$ & Free & Free & Constrained & Free \\
\hline
\end{tabular}

The initial global, local and sideway shifting imperfections are applied. The procedure and the assumptions (perfect welding, perfect cleaning, etc.) are adopted. The aspect ratio of the plate is defined as:

$$
A R_{\text {plate }}=l / b
$$

In this case, the number of half waves, $m$, in the longitudinal direction are equal to 3 . The finite element type used in the non-linear FE analysis is shell element SHELL181. This element has four nodes with six degrees of freedom at each node. SHELL181 is well-suited for a large rotation, and considerable strain nonlinear applications. The FE analyses are performed using the commercial software ANSYS [41]. More information about the FE analyses may be found in [28]. Fig. 1 presents the normalized stress-strain curve obtained from FE simulations. 


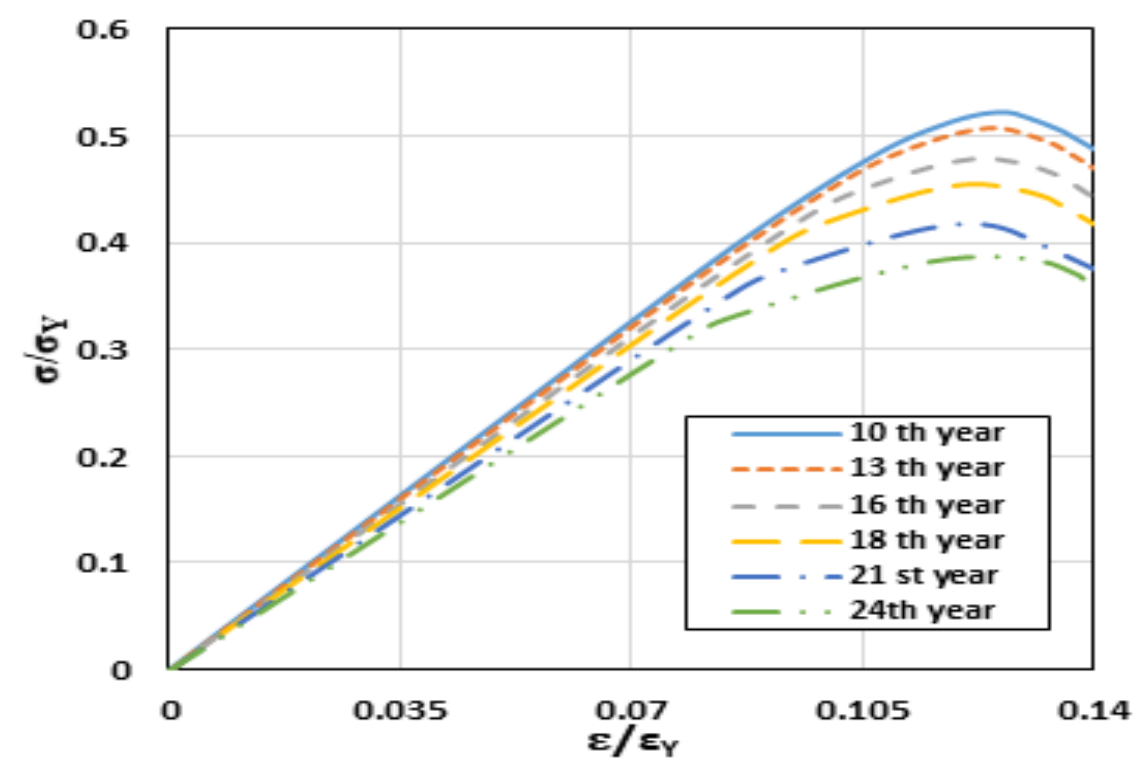

Fig. 1 - Normalized stress-strain curve for corroded plate $\left(10^{\text {th }}\right.$ to $24^{\text {th }}$ year $)$

\section{Failure assessment}

The ultimate limit state function of the longitudinal girder plate with manhole under uniaxial compression is defined as [42]:

$$
g(t)=\tilde{x}_{u} S \widetilde{M}_{C R}(t) \tilde{\sigma}_{u}(t)-\tilde{x}_{S W} \widetilde{M}_{S W}-\tilde{x}_{w} \tilde{x}_{s} \widetilde{M}_{w}
$$

where $S \widetilde{M}_{C R}(t)$ is the midship section modulus, $\tilde{\sigma}_{u}(t)$ is the ultimate stress, $\widetilde{M}_{S W}$ is the still water bending moment, $\widetilde{M}_{w}$ is the wave-induced bending moment, $\tilde{x}_{u}$ is the model uncertainty on the ultimate strength, $\tilde{x}_{S W}$ is the uncertainty in the model of predicting the still water bending moment, $\tilde{x}_{w}$ is the uncertainty in the estimation of the wave-induced bending moment due to linear analysis and $\tilde{x}_{s}$ takes into account non-linearity and the statistical descriptors of the uncertainty factors are assumed as:

$$
\begin{gathered}
\tilde{x}_{u} \sim N\{1 ; 0.15\} \\
\tilde{x}_{S W} \sim N\{1 ; 0.05\} \\
\tilde{x}_{w} \sim N\{0.9 ; 0.14\} \\
\tilde{x}_{s} \sim N\{1.15 ; 0.03\}
\end{gathered}
$$

where $\mathrm{N}$ indicates the Normal distribution function, the first term inside brackets is the mean value, and the second term is the standard deviation. The analysis is performed for a Panamax Tanker with the following main dimensions: the length between perpendicular, $L=208 \mathrm{~m}$, beam, $B=32.25 \mathrm{~m}$, depth, $D=16.125 \mathrm{~m}$, draught, $d=9.5 \mathrm{~m}$, block coefficient, $C b=0.8$, deadweight, $D W=75,000$ tons and lightweight, $L W=9,304$ tons.

The time-dependent variation of the Section Modulus $S M(t)$ has been derived taking into account the general corrosion of the structural components of the midship section, plates and stiffeners, accounting for the different environment conditions associated to the location of the plates and the corrosion addiction, $t_{c}$, as stipulated by CSR. In the present study, the 
environmental coefficients as derived in [39] are employed.

Table 2 - Long-term corrosions, transition times and coating lives considered in the study

\begin{tabular}{|c|c|c|c|c|c|c|c|}
\cline { 2 - 8 } \multicolumn{1}{c|}{} & $\boldsymbol{d}_{\infty \boldsymbol{1}}$ & $\boldsymbol{d}_{\infty 2}$ & $\boldsymbol{\tau}_{\boldsymbol{t} \mathbf{1}}$ & $\boldsymbol{\tau}_{\boldsymbol{t} \mathbf{2}}$ & $\boldsymbol{\tau}_{\boldsymbol{c} \boldsymbol{1}}$ & $\boldsymbol{\tau}_{\boldsymbol{c} \boldsymbol{2}}$ & case \\
\hline \multirow{5}{*}{ Plates } & 0.78 & 0.65 & 13.35 & 11.97 & 3.17 & 3.17 & 1 \\
\cline { 2 - 8 } & 0.78 & 0.97 & 13.35 & 15.05 & 3.17 & 3.17 & 2 \\
\cline { 2 - 8 } & 0.78 & 0.56 & 13.35 & 10.92 & 3.17 & 11.49 & 3 \\
\cline { 2 - 8 } & 0.93 & 0.56 & 14.7 & 10.92 & 10.54 & 11.49 & 4 \\
\cline { 2 - 8 } & 0.96 & 0.93 & 14.94 & 14.7 & 11.49 & 10.54 & 5 \\
\cline { 2 - 8 } & 0.96 & 0.96 & 14.94 & 14.94 & 11.49 & 11.49 & 6 \\
\cline { 2 - 8 } & 0.78 & 0.78 & 13.35 & 13.35 & 3.17 & 3.17 & 7 \\
\cline { 2 - 8 } & 0.93 & 0.96 & 14.7 & 14.94 & 10.54 & 11.49 & 8 \\
\cline { 2 - 8 } & 0.78 & 0.56 & 13.35 & 10.92 & 3.17 & 11.49 & 9 \\
\cline { 2 - 8 } & 1.18 & 0.78 & 16.55 & 13.35 & 11.49 & 3.17 & 10 \\
\hline \multirow{5}{*}{ Stiffeners } & 0.78 & 0.78 & 13.35 & 13.35 & 3.17 & 3.17 & 11 \\
\cline { 2 - 8 } & 0.93 & 0.93 & 14.7 & 14.7 & 10.54 & 10.54 & 12 \\
\cline { 2 - 8 } & 0.96 & 0.96 & 14.94 & 14.94 & 11.49 & 11.49 & 13 \\
\hline
\end{tabular}

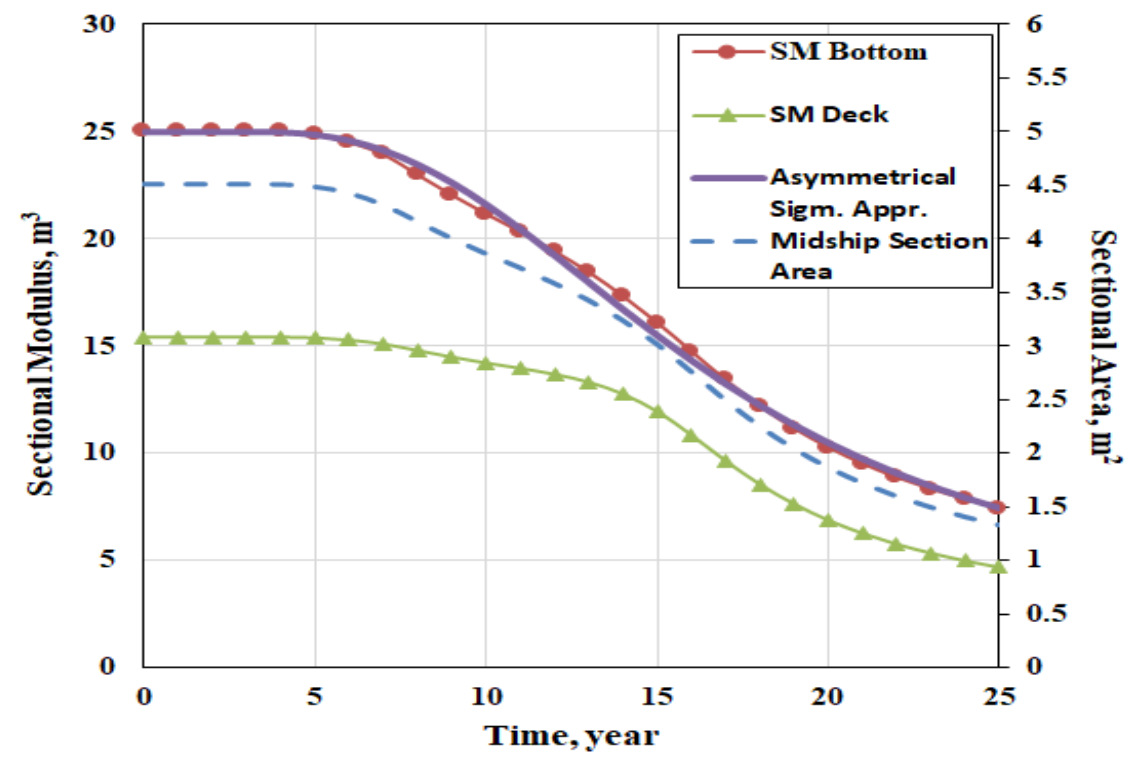

Fig. 2 - Midship section modulus and area as a function of time

The different long-term corrosion wastages, $d_{\infty_{1}}$ and $d_{\infty_{2}}$, the coating lives, $\tau_{c_{1}}$ and $\tau_{c_{2}}$, and the transition time, $\tau_{t_{1}}$ and $\tau_{t_{2}}$, for the two sides of the plate are present in Table 2: case 1 is considered for the bottom plating, case 2 for the bilge plating, case 3 for the side shell plating, case 4 for the shell plating within 3 meters below top of tank, case 5 for the weather deck plating/ballast tank, case 6 for the weather deck plating/cargo hold, case 7 for the longitudinal girder, case 8 for the longitudinal bulkhead/cargo-ballast plating (within 3 meters below top of tank), case 9 for the longitudinal bulkhead/cargo-ballast plating (elsewhere), case 10 for the inner bottom plating/bottom of tank. Exclusively for the stiffeners, the following cases are used: case 10 for the ballast tank stiffener (elsewhere), case 11 for the ballast tank stiffener (within 3 
meters below the top of tank) and case 12 for the cargo oil tank stiffener.

Fig. 2 presents the section moduli estimated at the level of the deck and bottom and the midship section area as a function of time due to the adopted corrosion degradation of structural components. It can be seen that the midship section modulus at the level of the bottom is more severely reduced by the corrosion degradation, which may be explained by the lower coating protection life and, in consequence, the corrosion wastage initiates earlier.

A general time-dependent relationship for the midship section modulus is derived following the asymmetrical sigmoidal function developed here as:

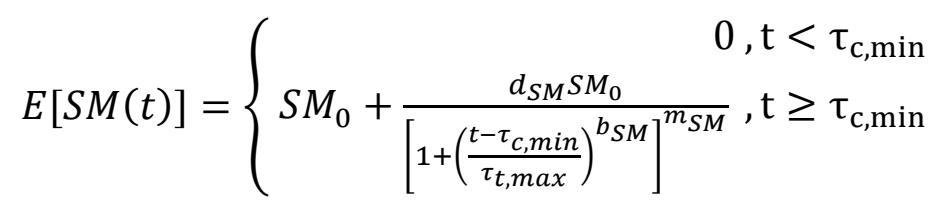

where $S M_{0}$ is the intact section modulus, $\tau_{c, \min }$ is the lowest value of coating life among structural components of the midship section, $\tau_{t, \max }$ is the highest time of the transition among the structural elements of the midship section, $d_{S M}, b_{S M}$ and $m_{S M}$ are coefficients equal to $0.90,3.68$ and -0.7 .

The midship section modulus, $S M(t)$, is considered to be described by the Log-Normal distribution with a mean value of $E[S M(t)]$ and standard deviation:

$$
\operatorname{StDev}[S M(t)]=S M_{0} *\left[a_{S M} * \ln (t)-c_{S M}\right]
$$

where the coefficients $a_{S M}$ and $c_{S M}$ are defined respectively as 0.1246 and 0.2273 .

$$
S M(t) \sim \operatorname{LogNormal}\{E[S M(t)] ; \operatorname{StDev}[S M(t)]\}
$$

The still water bending moment is fitted to the Normal distribution function [43]. It is assumed that the still water bending moment given by the CSR is the maximum value with a probability of exceedance of 5\%. The significant variability in the still water bending moment results in a coefficient of variation of $40 \%$, which gives the mean value of the distribution to be $60 \%$ of $M_{S W, C S}$ :

$$
M_{S W, C S} \sim N\left\{0.6 M_{S W, C S} ; 0.24 M_{S W, C S}\right\}
$$

If the wave-induced loads can be represented as a stationary Gaussian process (short-term analysis) then the wave-induced bending moment given by the CSR may be modelled as an extreme value following the Gumbel distribution function [44]:

$$
\begin{gathered}
F_{w}(\omega)=\exp \left\{-N_{w} \exp \left(-\frac{\omega^{2}}{2 \lambda_{0}}\right)\right\} \\
\mu_{w}=M_{w, C S}=\sqrt{2 \lambda_{0} \ln \left(N_{w}\right)}+\frac{0.5772}{\sqrt{2 \lambda_{0} \ln \left(N_{w}\right)}} \\
\sigma_{w}=\frac{\pi}{\sqrt{6}} \sqrt{\frac{\lambda_{0}}{2 \ln \left(N_{w}\right)}}
\end{gathered}
$$

where $\mu_{w}$, is the mean value and $\sigma_{w}$ is the standard deviation, $N_{w}$ is the number of wave induced bending moment peaks and $\lambda_{0}$ is the mean square of the wave induced bending moment. The 
wave induced bending moment, given by the CSR, is assumed to be the mean value and when $N_{w}$ is about 1000 and it is equivalent to a 3 hours storm and gives a coefficient of variation of $9 \%$.

The analysed plate to be retrofitted is a side girder located in the inner bottom of a tanker ship, and according to CSR, the required bending moments and the sectional modulus are:

$$
\begin{gathered}
M_{S W, C S R}=1521.348[\mathrm{MNm}] \\
M_{W, C S R}=2092.714[\mathrm{MNm}] \\
S M_{C S R}=25.005\left[\mathrm{~m}^{3}\right]
\end{gathered}
$$

The ultimate strength of the corroded plate $\sigma_{u}$ is modelled by the Log-Normal distribution function:

$$
\sigma_{U}(t) \sim \operatorname{LogNormal}\left\{E\left[\sigma_{U}(t)\right] ; 0.05\right\}
$$

The mean value of the ultimate strength concerning the time, $E\left[\sigma_{U}(t)\right]$, is described by an asymmetrical sigmoid function developed here, when the corrosion starts to act on the plate.

$$
E\left[\sigma_{U}(t)\right]=\left\{\begin{array}{c}
a_{A x S g} * \sigma_{Y P} t<\tau_{c} \\
c_{A x S g} * \sigma_{Y P}+\frac{d_{A x S g^{*}} \sigma_{Y P}}{\left[1+\left(\frac{t-\tau_{c}}{\tau_{t}}\right)^{b_{\sigma}}\right]^{m_{\sigma}}} \tau_{c} \geq t \geq 25 \text { years }
\end{array}\right.
$$

where $\sigma_{Y P}=355 \mathrm{MPa}$ is the yield stress of the material, the coating life $\tau_{c}=3.17$ years, the transition time $\tau_{t}=13.75$ years, the coefficients $a_{A x S g}, b_{\sigma} c_{A x S g}, d_{A x S g}$ and $m_{\sigma}$ are equal respectively to $0.5225,1.86,0.06,0.46,6.69$. The standard deviation has been assumed as 0.05 .

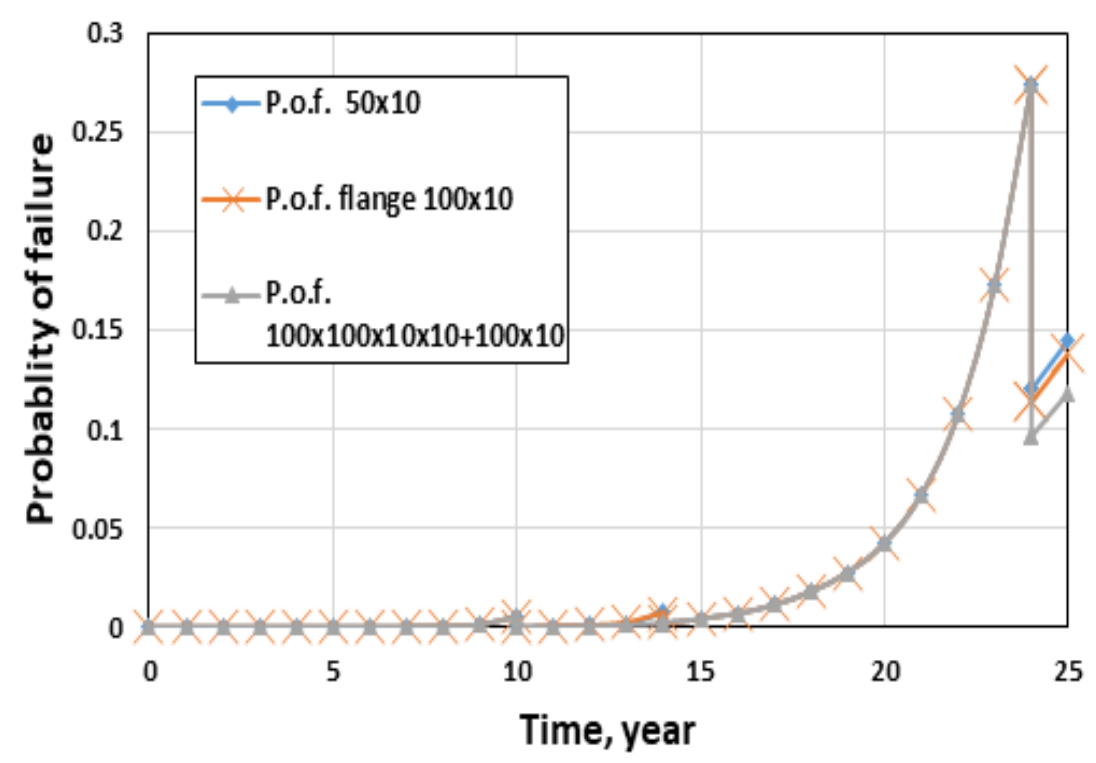

Fig. 3 - Probability of failure of scenario "b", "e" and "i".

The probability of failure along the 25 -year-service life of the vessel, using the limit state 
function as is defined by Eqn 4 and employing the FORM [45] with the commercial software COMREL [46]. For the different scenarios, the probability of failure as a function of time, conditional to the retrofitting at $10^{\text {th }}$ and $24^{\text {th }}$ year, and replacement at the $14^{\text {th }}$ year is analysed. Fig. 3 presents the probability of failure of the plate retrofitted with two longitudinal stiffeners $50 \times 10$, flange 100x10 and two longitudinal and two transversal stiffeners 100x100x10x10.

It is noticeable that the drop in the probability of failure at year $24^{\text {th }}$ has a greater magnitude and impact on recovering the reliability of the structure than the ones occurring at $10^{\text {th }}$ and $14^{\text {th }}$ year. This can be explained with the fact that the midship section is less corroded and the "impact" of substitution or retrofit of a single plate at year $10^{\text {th }}$ and $14^{\text {th }}$ is not effective in the global scale while it is at the $24^{\text {th }}$ year.

\section{Cost-benefit analysis}

A cost-benefit analysis has been performed to provide the best solution associated with the containment of costs and safety. The study focuses on defining the optimum safety level combined with the cost of the retrofit of a corroded side girder plate and the reduction of risk. The risk, $R$ is defined as a product of the probability of failure, $\mathrm{P}_{\mathrm{f}}$, times the associated consequences, $C$ :

$$
R=P_{f} * C
$$

The cost related to the structural failure of the ship, $C_{t}^{\beta_{t}}$ including the cost of the retrofit process is defined as:

$$
C_{t}^{\beta_{t}}=C_{T f}^{\beta_{t}}+C_{m e}^{\beta_{t}}+C_{\text {retrofitting }}^{\beta_{t}}
$$

where $C_{T f}^{\beta_{t}}$ is the cost associated with the structural failure of the ship, $C_{m e}^{\beta_{t}}$ is the cost associated to the structural redesign of the new ship and $C_{\text {retroffiting }}^{\beta_{t}}$ is the cost associated with the structural retrofitting process.

The cost of the structural failure of the ship includes four major groups:

$$
C_{T f}^{\beta_{t}}=\sum_{t=1}^{t} P_{f}(t)\left[C_{n}(t)+\left(C_{c}+C_{d}+C_{v}\right)\right] e^{-\gamma t}
$$

where $P_{f}(t)$ is the probability of failure, $C_{n}(t)$ is the cost of the ship as a function of time, $C_{c}$ is the cost for the loss of cargo, $C_{d}$ is the cost for the accidental oil spilling and cleaning, $C_{v}$ is the cost for the loss of human life and $\gamma$ the discount rate, in this case taken as $5 \%$.

The cost of the ship is defined as a function of the time and the scrapping value, which has been linearly discounted during the service life of 25 years:

$$
C_{n}(t)=C_{n_{0}}-\left(C_{n_{0}}-C_{s c r a p}\right)\left(\frac{t}{25}\right)
$$

where $C_{n_{0}}$ is the initial cost of the ship and $C_{\text {scrap }}$ is the revenues for the scrapping of the ship. The initial value of the ship is an estimation of the current prices present in a market review in [47] as 38.0 M€. The revenues from scrapping the ship are defined as:

$$
C_{\text {scrap }}=C_{\text {steel/ton }} L W T
$$


where the cost of steel is assumed as $C_{\text {steel/ton }}=700 € /$ ton and $L W T$ is the lightweight of the vessel.

The cost due to the loss of cargo take into account as only $P_{\text {spill }}=20 \%$ of the total cargo carried to be spill caused by the structural failure of the ship, [48]:

$$
C_{c}=C_{\text {crude } / \text { ton }} * D W T * P_{\text {spill }}
$$

where the cost of a ton of crude oil is assumed as $C_{\text {crude/ton }}=62 € /$ ton, [49], $P_{\text {spill }}$ is the percentage of oil spilt caused by structural failure and DWT is the deadweight of the vessel.

A fraction of the total spilt oil due to structural failure it is considered to be $10 \%$ of chance that the oil reaches shoreline [48], meaning that there are additional costs associated to it such as cleaning. In this case, the additional costs are estimated employing the CATS criterion:

$$
\mathrm{C}_{\mathrm{d}}=\mathrm{P}_{\text {spill }} * \mathrm{P}_{\mathrm{sl}} * \text { CATSDWT }
$$

where CATS is assumed to be $50,000 €$, which is the Cost of Averting a Ton of oil Spilt, $P_{s l}=$ $10 \%$ as the probability of the oil spilt reaching the shoreline.

The probability of loss of crew for this study is assumed to be $25 \%$, [50]:

$$
C_{v}=n_{\text {crew }} * P_{\text {crew }} I C A F
$$

where $n_{\text {crew }}=25$ is the number of the crew members, $P_{\text {crew }}=25 \%$ is the probability to avert a fatality, ICAF $=3.30$ millions of euros is the cost of the occurrence of the fatality.

Due to corrosion degradation, the structural components lose their stiffness and the cost of the steel ship structure as a function of time is defined as:

$$
\begin{gathered}
C_{m e}^{\beta_{t}}=(1-I S M(t)) W_{\text {steel }} C_{\text {steel }} \\
I S M(t)=A(t) / A(0)
\end{gathered}
$$

where $\operatorname{ISM}(t)$ is the steel reduction due to corrosion measured as a function of time, $A(t)$ is the midship section area as a function of time, $t, A(0)$ is the intact midship section area, $W_{\text {steel }}$ is the weight of steel and $C_{\text {steel }}$ is the cost of steel per ton.

The current study focuses on the retrofitting process to regain the ultimate strength capacity of the girder plate in the double bottom with a man-hole opening. This process takes into account two different aspects: the retrofitting performed and the strategy to apply it.

The retrofit occurs when the steel plate's ultimate strength capacity drops below $75 \%$ of intact ultimate strength capacity and in the present study occurs at the $10^{\text {th }}$ and $24^{\text {th }}$ year, while at the $14^{\text {th }}$ year, the plate as to be replaced due to reaching the minimum acceptable thickness $(3 \mathrm{~mm})$, as shown in Fig. 4. 


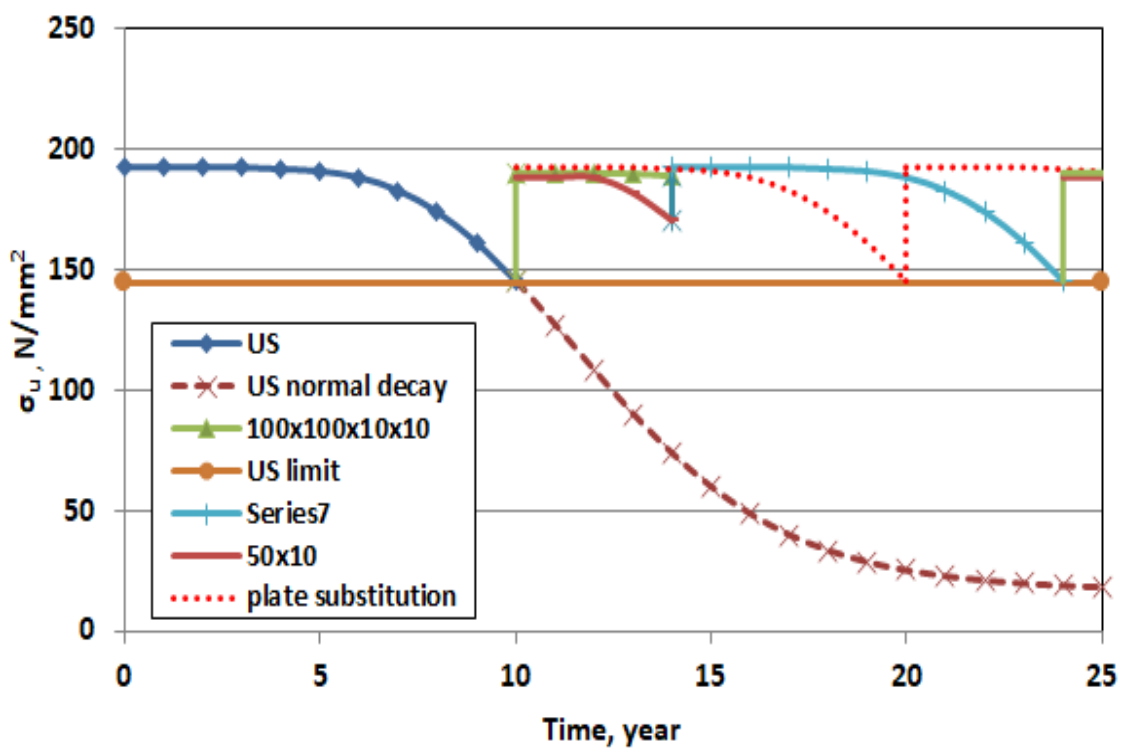

Fig. 4 - Ultimate strength of retrofitted plate ( 2 x 50x10 stiffeners, $2 \times 100 \times 100 \times 10 \times 10$, plate substitution) vs corroded plate.

Table 3 shows different solutions adopted in the current study, where cases $b, c$ and $d$ are representing the reinforcement of the corroded plate with 2 longitudinal stiffeners, $e, f$, and $g$, the reinforcement is performed by a flange on the opening and $i, j, k$ by 2 longitudinal and 2 transversal stiffeners and the case $l$ a box does the reinforcement.

Table 3 - Retrofitting solutions adopted.

\begin{tabular}{|c|c|c|}
\hline & Type & N. Scenario \\
\hline Only plate & Plate & $\mathbf{a}$ \\
\hline \multirow{3}{*}{2 Longitudinal stiffeners } & $50 \times 10$ & b \\
\hline & 100x100x10x10 & c \\
\hline & $300 \times 80 \times 10$ & d \\
\hline \multirow{3}{*}{ Flange on the opening } & flange $100 \times 10$ & $\mathbf{e}$ \\
\hline & flange $200 \times 10$ & $\mathbf{f}$ \\
\hline & flange $300 \times 17$ & $\mathbf{g}$ \\
\hline \multirow{5}{*}{$\begin{array}{c}2 \text { Longitudinal stiffeners } \\
+2 \text { Transversal } \\
\text { stiffeners }\end{array}$} & $50 \times 10+50 \times 10$ & h \\
\hline & $100 \times 100 \times 10 \times 10+100 \times 10$ & $\mathbf{i}$ \\
\hline & $300 \times 80 \times 10 \times 10+300 \times 8$ & $\mathbf{j}$ \\
\hline & $300 \times 80 \times 10 \times 10+300 \times 20$ & $\mathbf{k}$ \\
\hline & box & 1 \\
\hline
\end{tabular}

The cost of the retrofitting is defined as:

$$
C_{\text {retrofitting }}^{\beta_{t}}=\left(C_{\text {Capex }}+C_{\text {associated }}\right)+C_{\text {Strategy }}
$$

where $C_{\text {Capex }}$ is the cost of material, manufacturing and installation of the reinforcement on the plate as defined in [28], $C_{\text {associated }}$ is the cost associated to the access to the location of the retrofitted plate, including cleaning, lighting, opening and closing the tanks and tank testing, 
and $C_{\text {Strategy }}$ is the cost associated with the strategy adopted:

$$
C_{\text {associated }}=n_{\mathrm{S}} A_{S}+C_{S}+C_{S T}
$$

where $n_{S}$ is the number of accesses to open and reach the working space, $A_{S}$ is the cost to access the space, $C_{S}$ is the cost of cleaning, lighting, opening and closing the tanks and $C_{S T}$ the cost to test the water tightness.

In this study, the strategy cost is taken into account only when the entire plate has to be replaced. Four different strategies are taken into account, and they are shown in Fig. 5.

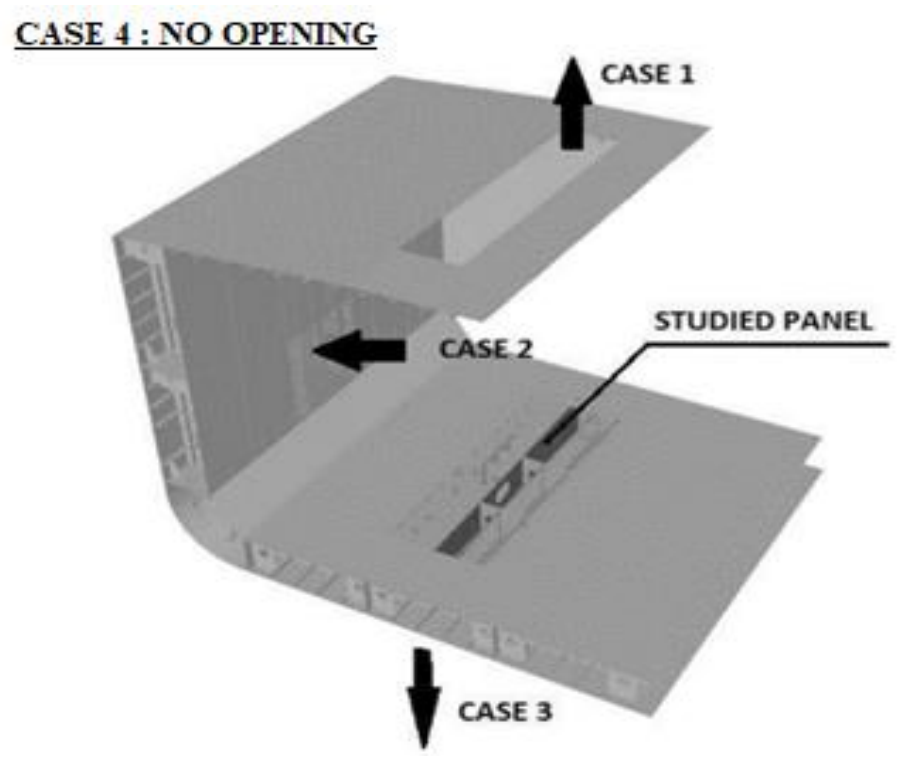

Fig. 5 - Plate substitution strategies

Case 1 takes into account that the access to the inner bottom is done from the deck with an opening of $4 \times 1$ meters, Case 2 from the side with an opening of $2 \times 2$ meters, Case 3 from the bottom with an opening $4 \times 1$ meters and Case 4 the access is done without creating openings in the hull. Case 1 and Case 2 also comprehend the necessity to create an opening on the inner bottom of 4 x 1 meters. The strategy cost, $C_{\text {Strategy }}$ is defined as:

$C_{\text {plates }} C_{\text {Strategy }}=n_{1} A_{B T}+n_{2} A_{O T}+C_{B C}+C_{O C}+n_{3} C_{\text {Drydock }}+C_{B T, t}+C_{O T, t}+C_{d, u}+$

where $A_{B T}$ is the cost to access the ballast tank, $A_{O T}$ is the cost to access the oil tank, $C_{B C}$ is the cost of cleaning the ballast tank, $C_{O C}$ is the cost of cleaning the oil tank, $C_{\text {Drydock }}$ is the cost associated to drydock, $C_{B T, t}$ is the cost of testing the ballast tank, $C_{O T, t}$ is the cost of testing the oil tank, $C_{d, u}$ is the cost associated to docking and undocking of the ship, $C_{\text {plates }}$ is the cost of the plates to replace, $n_{1}$ and $n_{2}$ are the numbers of accesses to open in the ballast and oil tanks, $n_{3}$ is the number of day in the drydock. In this case study $n_{1}=6$ days and $n_{2}=6$ days, $n_{3}=4$ days. Those values are susceptive to difference due to different structural arrangement, for the openings, and to dry dock time and in an association to deeper works on the vessel such as multiple repairs or surveys. Table 4 shows the cost for each process related to the chosen strategy. 
Table 4 - Cost associated with considered strategies.

\begin{tabular}{|l|c|c|c|c|c|}
\hline \multicolumn{1}{|c|}{ Process } & $\begin{array}{c}\text { Deck } \\
\text { opening }\end{array}$ & $\begin{array}{c}\text { Side } \\
\text { opening }\end{array}$ & $\begin{array}{c}\text { Bottom } \\
\text { opening }\end{array}$ & $\begin{array}{c}\text { No } \\
\text { opening }\end{array}$ & \\
\hline Tank access & 425 & 425 & & & {$[€]$} \\
\hline Ballast tank access & 425 & 845 & 425 & 425 & {$[€]$} \\
\hline Ballast Tank cleaning & 3300 & 4960 & 3300 & 3300 & {$[€]$} \\
\hline Oil tank cleaning & 23400 & 23400 & & & {$[€]$} \\
\hline Dry dock & 93600 & 93600 & 93600 & 93600 & {$[€]$} \\
\hline Tank testing & 75 & 115 & 75 & 75 & {$[€]$} \\
\hline Oil tank testing & 16775 & 16775 & & & {$[€]$} \\
\hline Docking & 4095 & 4095 & 4095 & 4095 & {$[€]$} \\
\hline Undocking & 4095 & 4095 & 4095 & 4095 & {$[€]$} \\
\hline & & & & & {$[€]$} \\
\hline Cost of replace study plate & 10385 & 10385 & 10385 & 10385 & {$[€]$} \\
\hline $\begin{array}{l}\text { Cost of replacing inner bottom } \\
\text { plate }\end{array}$ & 6870 & 6870 & & & {$[€]$} \\
\hline Cost of replacing deck plate & 6870 & & & & {$[€]$} \\
\hline Cost of replacing side plate & & 6400 & & & {$[€]$} \\
\hline Cost of replacing bottom plate & & & 10382 & & {$[€]$} \\
\hline
\end{tabular}

The retrofitting (twice per service life) and plate replacement (once per service life, except scenario one where there are two replacements) cost per solutions adopted in comparison to the different strategies are presented in Fig. 6 and Fig. 7.

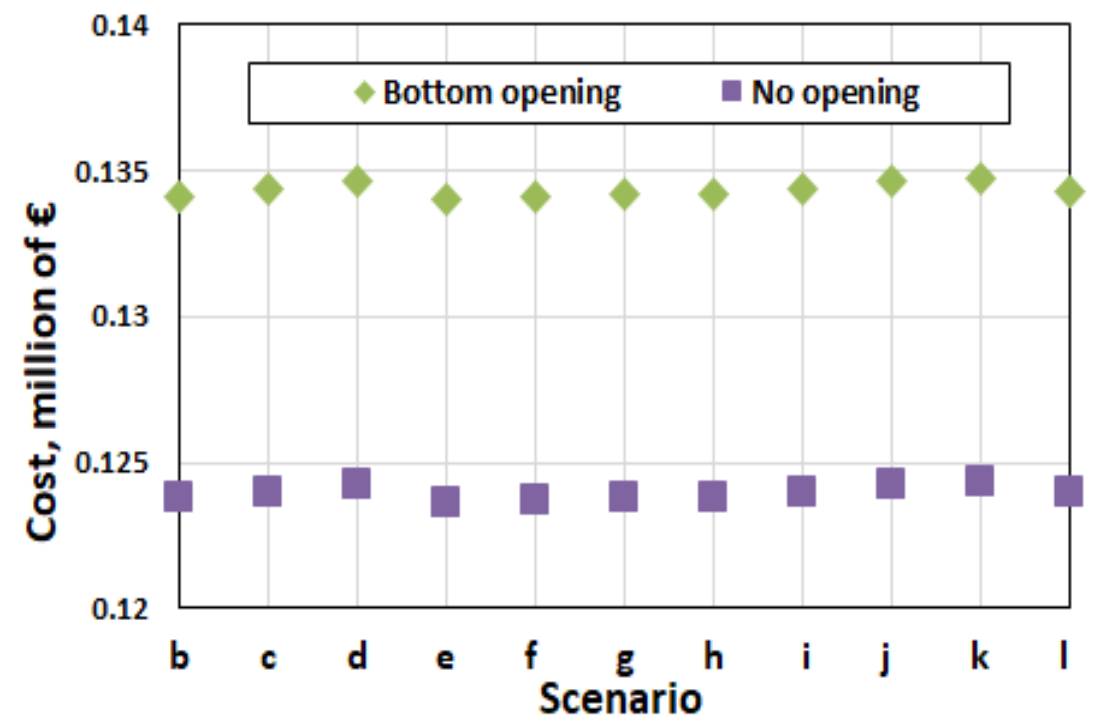

Fig. 6 - Total cost for different strategies: bottom opening and no opening

It is noticeable that the strategy with no openings in the hull is more economical than the bottom opening. 


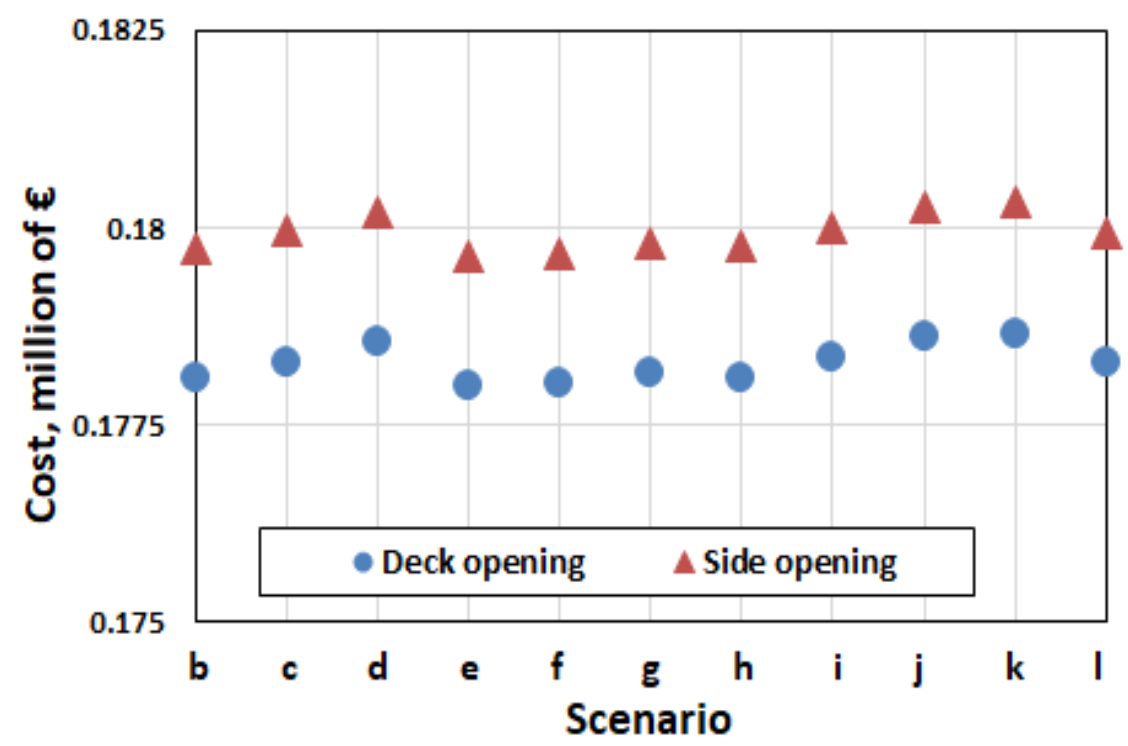

Fig. 7 - Total cost for different strategies: deck opening and side opening

In this case, the most economical solution is the strategy that provides access from the deck. Overall the most economical solutions are associated with the retrofitting processes conducted without or with a limited number of openings on the hull of the vessel. Table 5 reassumes the increase of cost for every scenario as a function of the most economical one: flange $100 \times 10$.

Table 5 - Comparison of costs in comparison of most economical (no opening "e")

\begin{tabular}{|l|c|c|c|c|c|c|c|c|c|c|c|c|}
\cline { 2 - 12 } \multicolumn{1}{c|}{} & $\mathbf{a}$ & $\mathbf{b}$ & $\mathbf{c}$ & $\mathbf{d}$ & $\mathbf{e}$ & $\mathbf{f}$ & $\mathbf{g}$ & $\mathbf{h}$ & $\mathbf{i}$ & $\mathbf{j}$ & $\mathbf{k}$ & $\mathbf{l}$ \\
\hline $\begin{array}{l}\text { Deck } \\
\text { op. }\end{array}$ & $175 \%$ & $44 \%$ & $44 \%$ & $44 \%$ & $44 \%$ & $44 \%$ & $44 \%$ & $44 \%$ & $44 \%$ & $44 \%$ & $44 \%$ & $44 \%$ \\
\hline $\begin{array}{l}\text { Side } \\
\text { op. }\end{array}$ & $\mathbf{1 7 8 \%}$ & $45 \%$ & $46 \%$ & $46 \%$ & $45 \%$ & $45 \%$ & $45 \%$ & $45 \%$ & $46 \%$ & $46 \%$ & $46 \%$ & $46 \%$ \\
\hline $\begin{array}{l}\text { Bottom } \\
\text { op. }\end{array}$ & $104 \%$ & $8 \%$ & $9 \%$ & $9 \%$ & $8 \%$ & $8 \%$ & $9 \%$ & $8 \%$ & $9 \%$ & $9 \%$ & $9 \%$ & $9 \%$ \\
\hline No op. & $88 \%$ & $0.1 \%$ & $0.26 \%$ & $0.46 \%$ & MIN & $0.03 \%$ & $0.13 \%$ & $0.10 \%$ & $0.29 \%$ & $0.50 \%$ & $1 \%$ & $0.2 \%$ \\
\hline
\end{tabular}

It can be observed that the strategies no opening and bottom opening have containment of the costs. In particular, the scenario "a" (substitution of the entire plate) is the worst possible solution concerning the real economic aspect of the retrofitting process.

The economic comparison (total cost) associated with the service life of the vessel is presented in Fig. 8. 


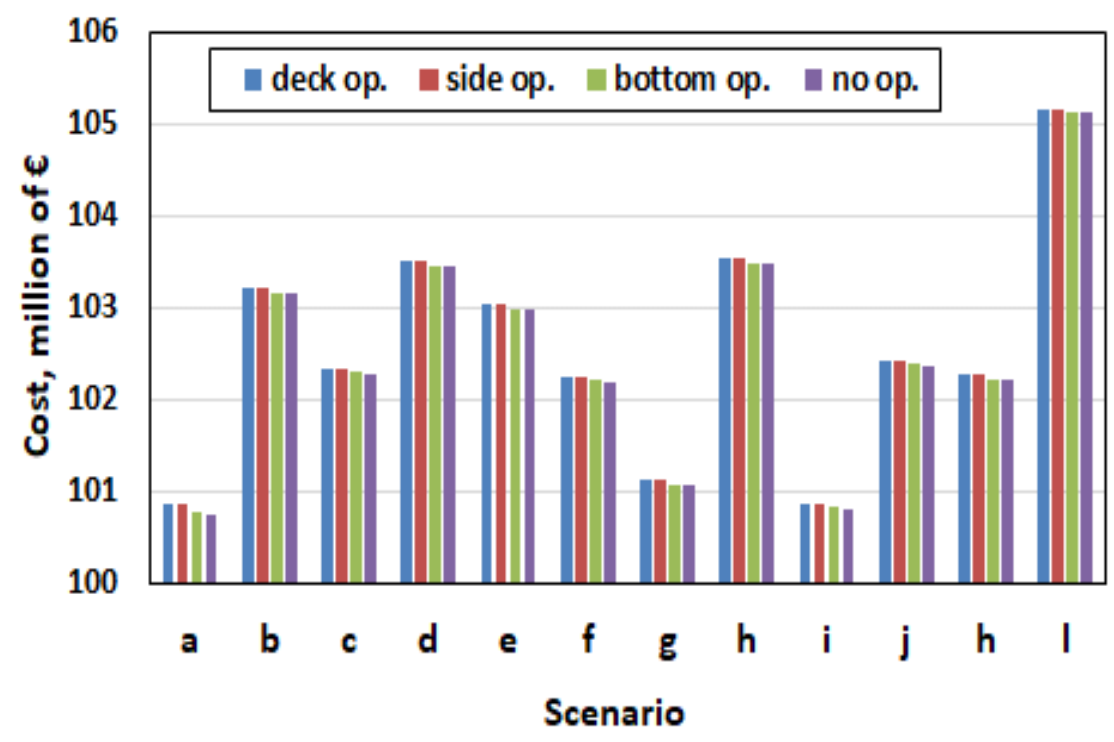

Fig. 8 - Total costs during service life ( 0 to $25^{\text {th }}$ year $)$

The total cost includes the mandatory substitution of the plate due to minimum thickness allowed by CSR for the scenarios from "b" to " 1 " with a total of three operations: the retrofit of the plate at the $10^{\text {th }}$ year, the substitution of the plate at $14^{\text {th }}$ year and retrofit of the new plate at the $24^{\text {th }}$ year. It is noticeable that the scenario " $a$ " is the most economical one. The explanation resides primarily in the difference of some operations: two against the three for the others. Such as for the scenario "g" (flange $300 \times 17)$ and "i" $(2 \times 100 \times 100 \times 10 \times 10+2 \times 100 \times 10)$ a better cleaning and coating protection could reduce the costs and prevent a second retrofitting process.

Fig. 9 presents the total cost associated with the time frame $10^{\text {th }}$ to $14^{\text {th }}$ year, the first retrofitting process to the replacement of the plate.

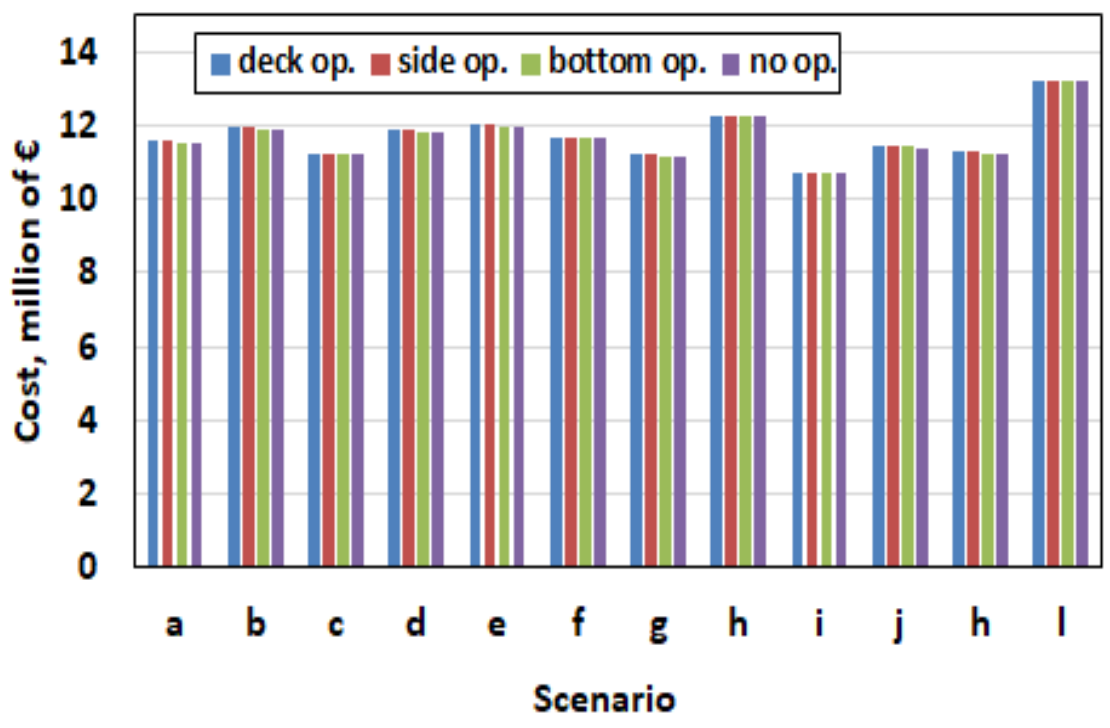

Fig. 9 - Total cost from $10^{\text {th }}$ to $14^{\text {th }}$ year

The total cost has a different distribution with all scenario residing on the same level. In particular, the scenario " $i$ " is the most economical solution regardless of the material used (2 longitudinal and two transversal stiffeners) in comparison to others such as the flange or the 
two longitudinal stiffeners. The difference in the cost between the strategies for the scenario "i" is negligible: the most economical one is the one with a no opening strategy, the bottom strategy presents a slight increase of costs in comparison of no opening strategy while side opening and deck opening have a moderate increase.

Fig. 10 presents the total costs associated with the time frame $14^{\text {th }}$ to $25^{\text {th }}$ year (substitution of the plate to end of service life).

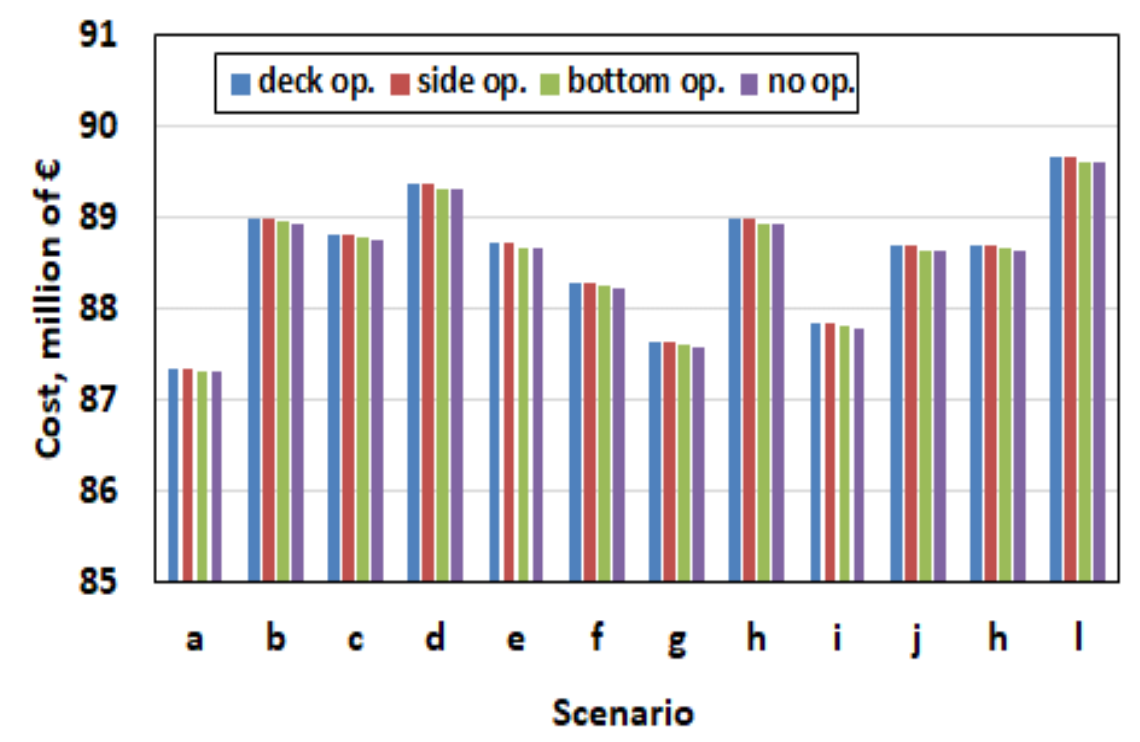

Fig. 10 - Total cost from $14^{\text {th }}$ to $25^{\text {th }}$ year

Also, in this case, the most economical solution is the substitution of the plate ("a"). Among the other scenarios, the "g" and "i" (respectively flange 300x17 and 2x100x100x10x10 + $2 \times 100 \times 10)$ are the most convenient ones.

The last time frame of interest, from the $24^{\text {th }}$ to the $25^{\text {th }}$ year (second retrofit process to the end of service life), is shown in Fig. 11.

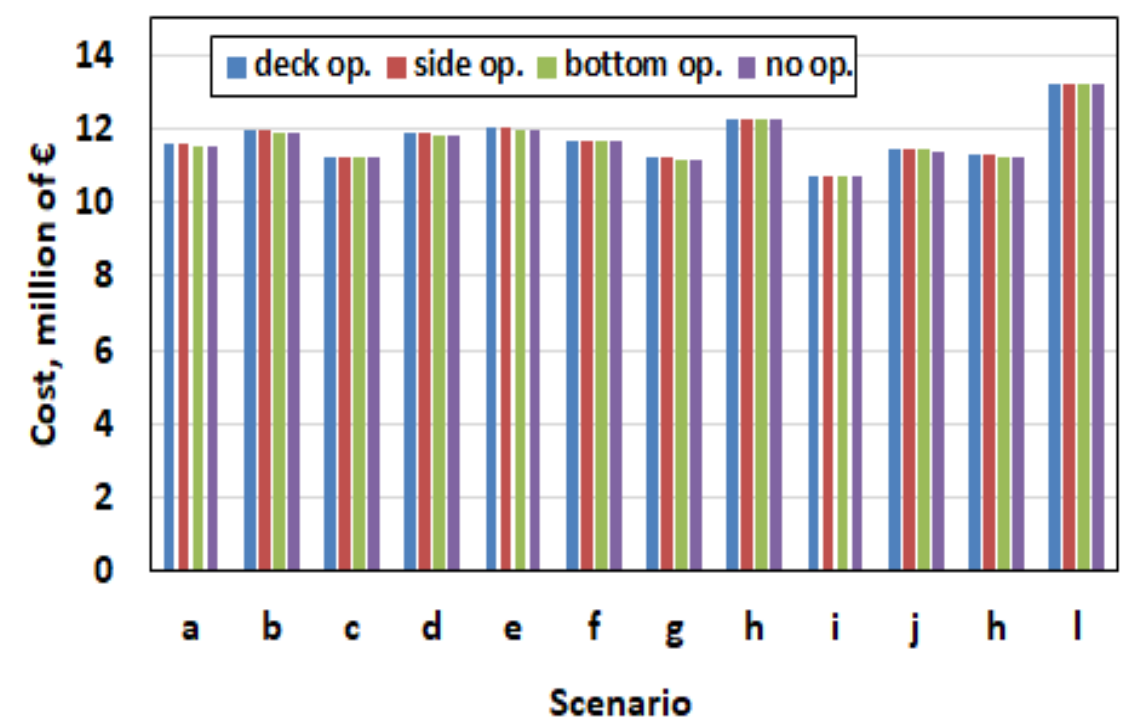

Fig. 11 - Total cost from $24^{\text {th }}$ to $25^{\text {th }}$ year 
The cost associated with the scenario "a" for this time frame is not comprehensive of the retrofit process. The replacement of the plate happens in the $20^{\text {th }}$ year. The solution more economical remains the "i" $(2 \times 100 \times 100 \times 10 \times 10+2 \times 100 \times 10)$.

In the present study, the risk is estimated for every strategy during the service life of the vessel. Fig. 12 presents the total risk for the strategy "no opening" during the 25 years of service (a) and the risk as a function of time (b).

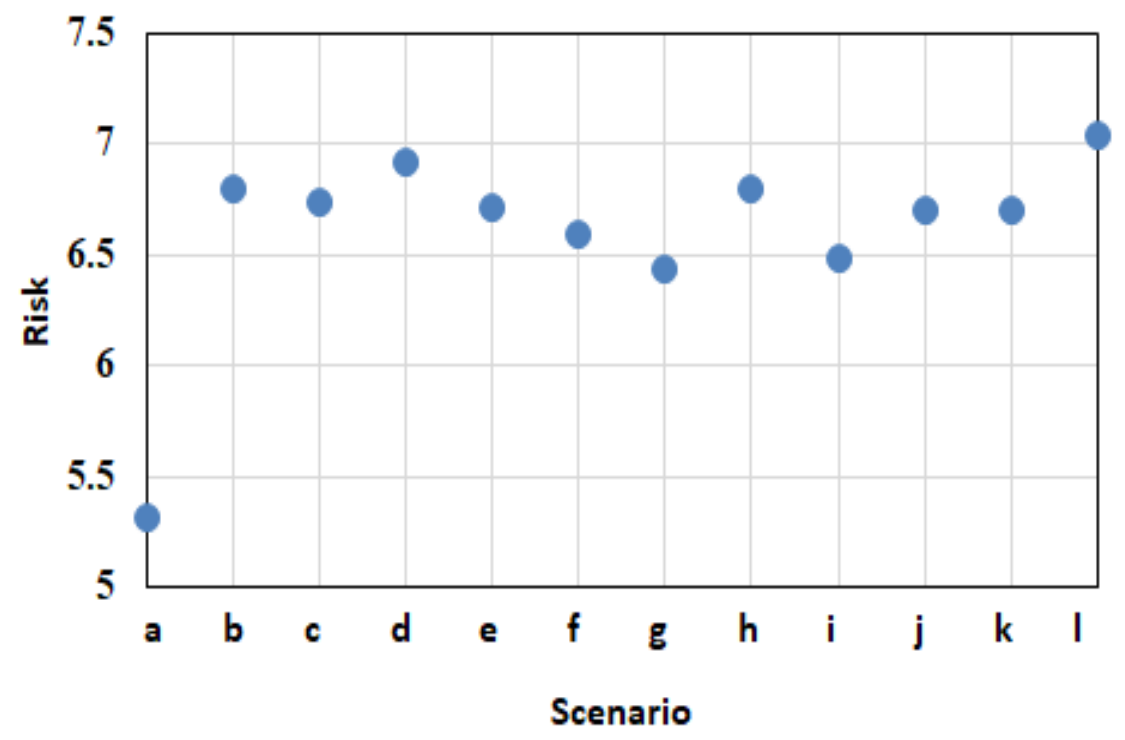

(a)

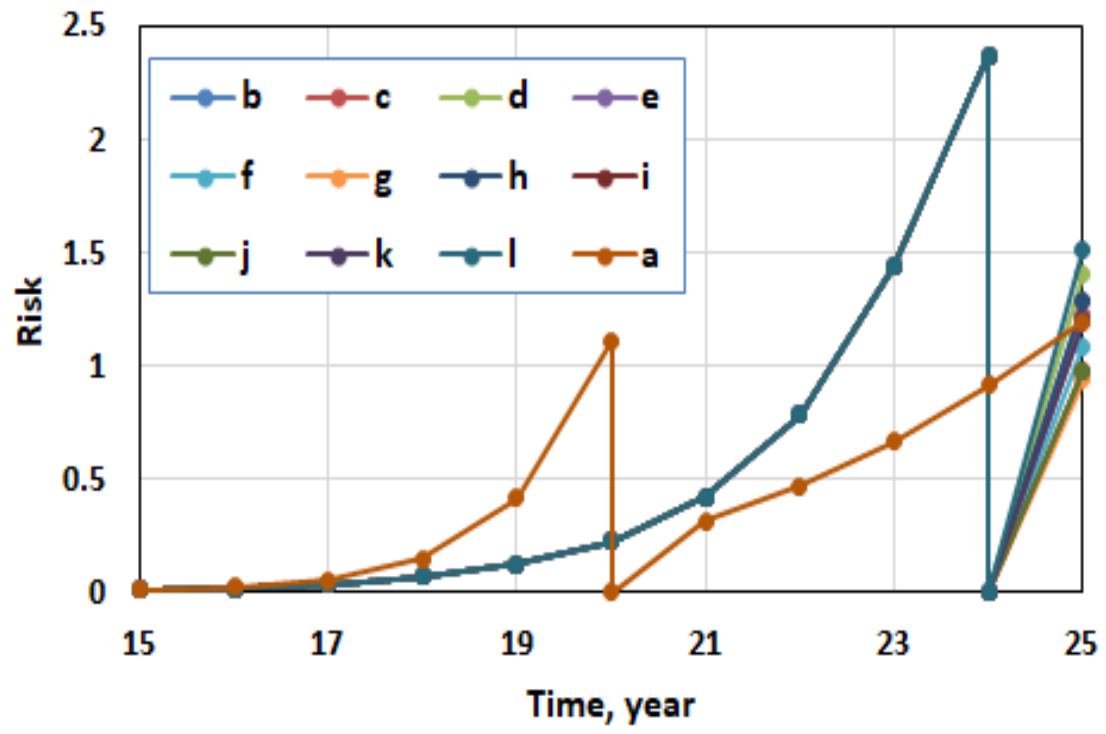

(b)

Fig. 12 - Total risk "no opening" strategy (a) and risk as a function of time (b)

The lowest risk during the service life is achieved by the scenario "a"; among the retrofit processes scenarios "g" and " $\mathrm{i}$ " have the lowest total risk. From Fig. 12 (b), it can be observed how the risk grows during the time due to the progressing of the corrosion of the entire structure and as well of the considered plate. In particular, while the growth of the risk has a similar pattern from year $15^{\text {th }}$ to $24^{\text {th }}$, the second retrofit process in year 24 shows different effectiveness for the scenarios considered. All four strategies show the same pattern of risk. The explanation resides in the fact that the total costs for different strategies for every scenario are negligible. 
The most substantial contribution to the total cost is given by the fixed costs that are the same for every case. A more detailed cost analysis would make sense of the difference between each strategy for each scenario.

An important aspect is given by the rate of increment of the risk between the year 24 and 25 as shown in Table 6.

Table 6 - Increment rate of risk from $24^{\text {th }}$ to $25^{\text {th }}$ years

\begin{tabular}{|c|c|c|c|c|c|c|c|c|c|c|}
\hline $\mathrm{b}$ & $\mathrm{c}$ & $\mathrm{d}$ & $\mathrm{e}$ & $\mathrm{f}$ & $\mathrm{g}$ & $\mathrm{h}$ & $\mathrm{i}$ & $\mathrm{j}$ & $\mathrm{k}$ & $\mathrm{l}$ \\
\hline $52.06^{\circ}$ & 50.88 & $54.57^{\circ}$ & $50.21^{\circ}$ & $47.37^{\circ}$ & $43.07^{\circ}$ & $51.98^{\circ}$ & $44.43^{\circ}$ & $50.03^{\circ}$ & $50.09^{\circ}$ & $56.58^{\circ}$ \\
\hline
\end{tabular}

As well for the cost comparison of the different retrofit scenarios, the solution " $\mathrm{i}$ " and " $\mathrm{g}$ " display a rate of an increase in the risk lower than the other cases.

The following scenarios are selected for additional analysis: "a", "g", "i" and "l". The selection is made by the minimum and maximum values of the cost and risk analysis. It is important to compare the scenarios "g" and "i" with the case with the substitution of the plate ("a") due to their close values with this last one. It is essential to verify the most expensive case in comparison with the most economical one.

Fig. 13 a, b, c, shows the comparison between the probability of failure and costs for the selected scenarios for the strategy related to the opening on the deck. Only one strategy is shown because the values among the different strategies have a negligible difference.

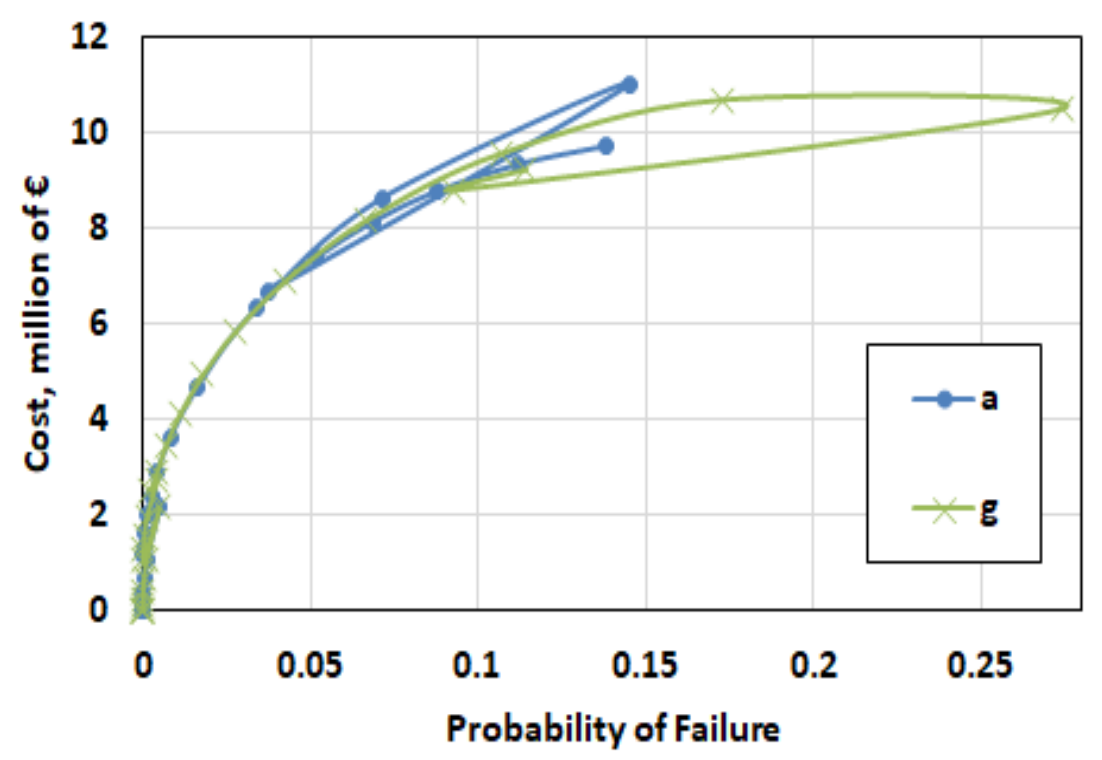

(a) 


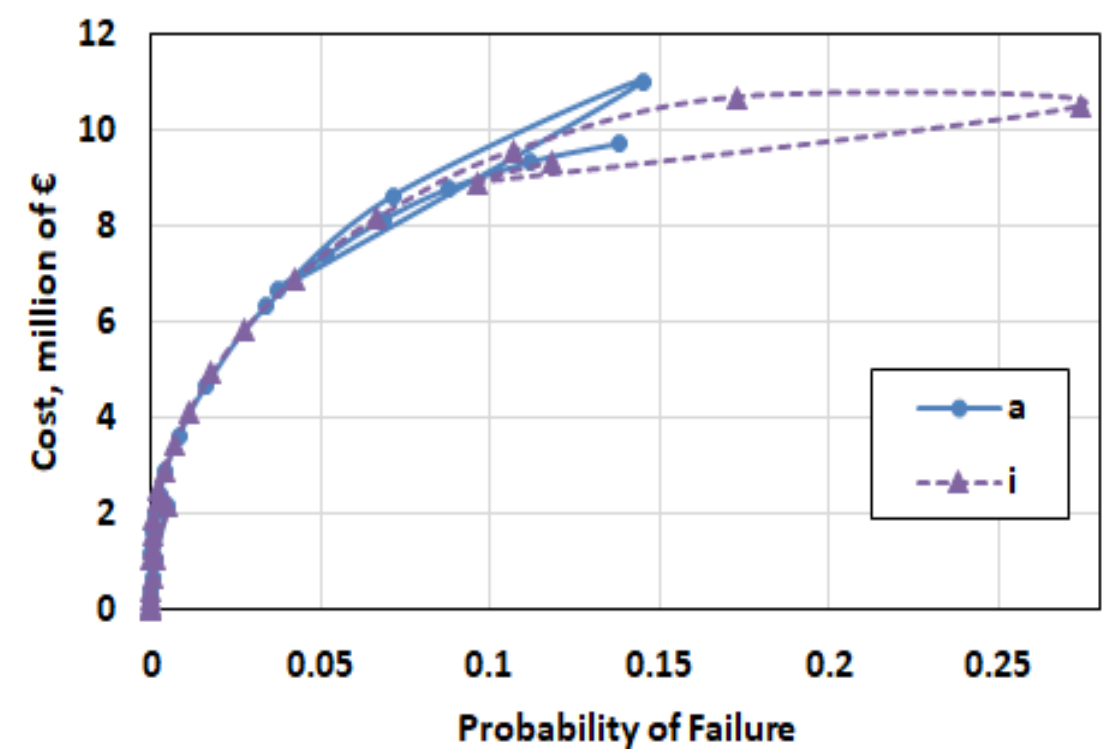

(b)

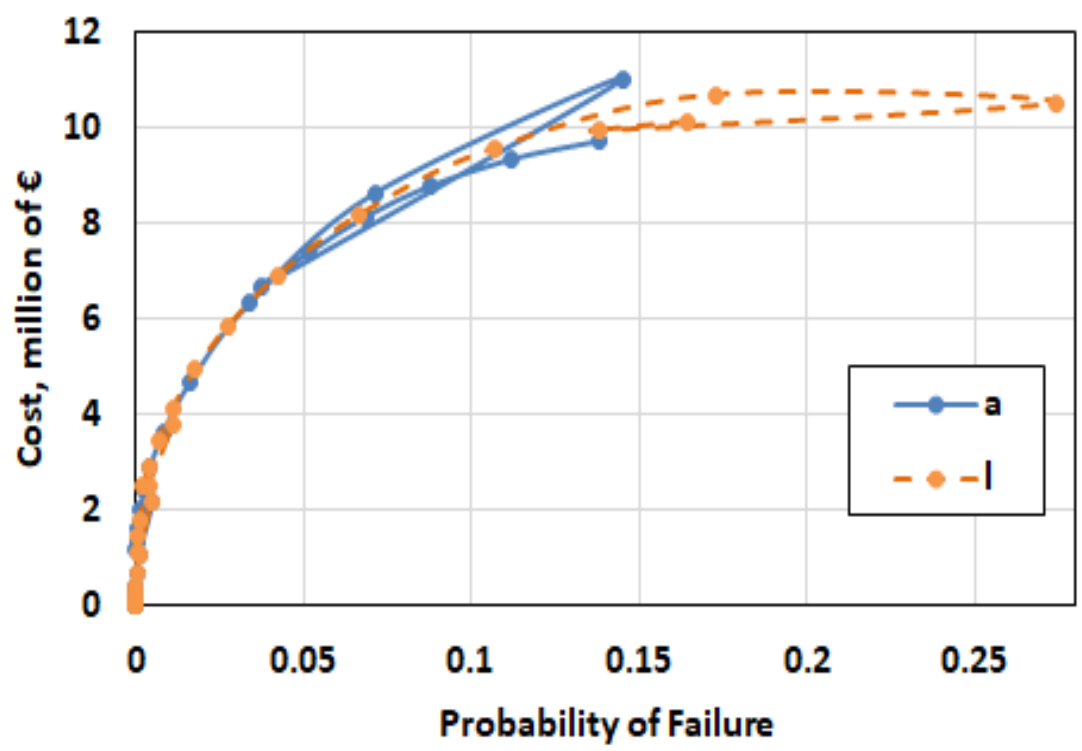

(c)

Fig. 13 - Probability of failure vs costs for "g", "i" and "l" in comparison to "a" scenario.

It is noticeable that all the scenarios with retrofitting, "g", "i" and "l" have the same maximum extension of the probability of failure. This is because after the $14^{\text {th }}$ year the original retrofitted plate is replaced with a new only at the $24^{\text {th }}$ year there is a new retrofitting process. The second retrofit can be appreciated with the different "amplitude" of the curves.

The comparison between the probability of failure and total costs between the case "a" and the retrofit scenario selected towards time is shown in Fig. 14 a, b, c. 


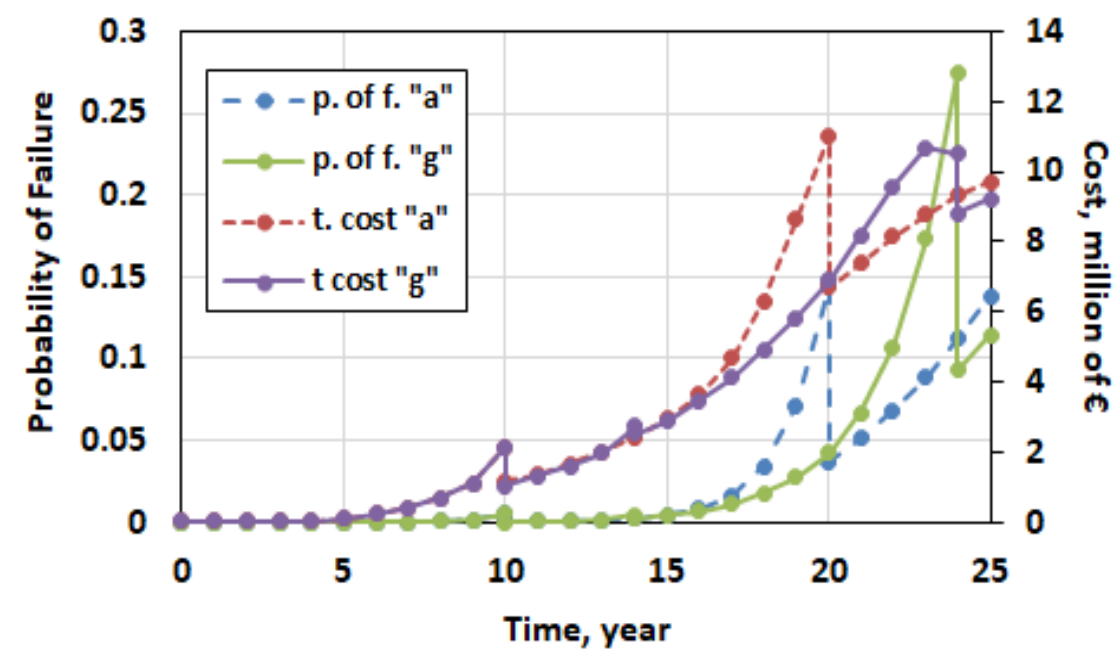

(a)

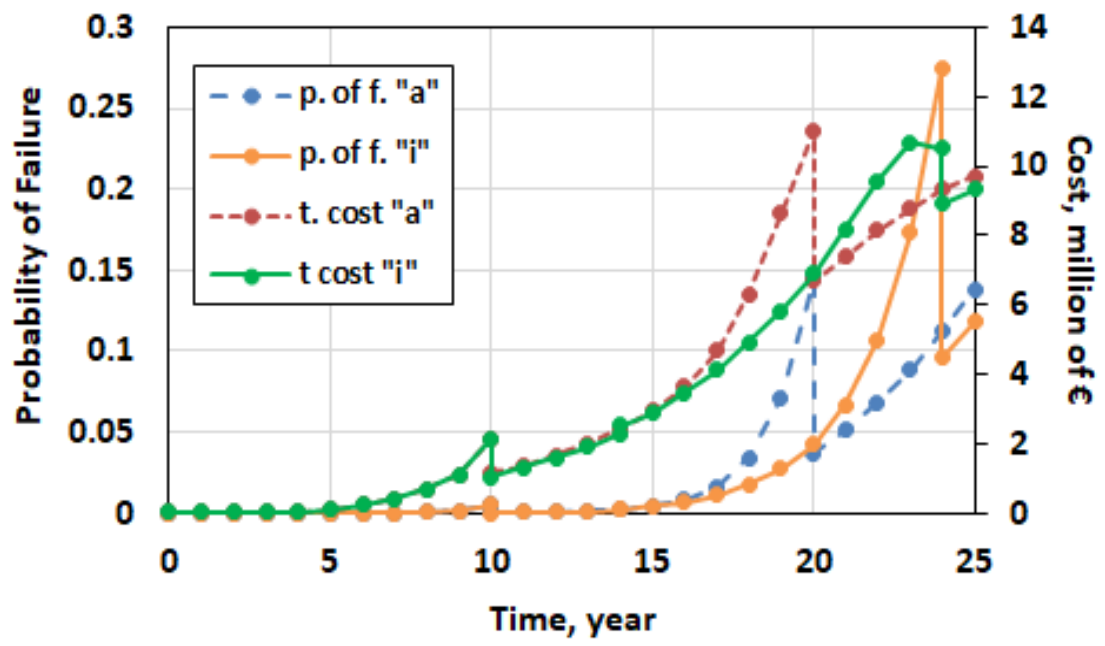

(b)

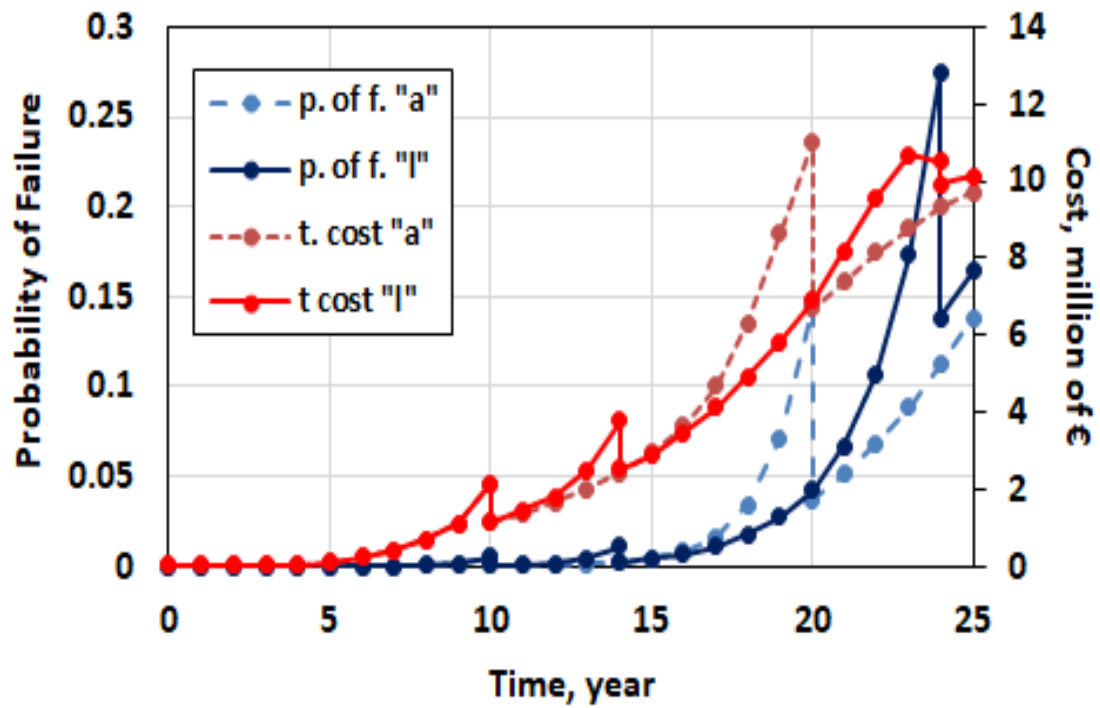

(c)

Fig. 14 - Probability of failure and total costs between the scenario "a" and "g", "i" and "l." 
It is noticeable that while the total cost of the retrofitted scenarios is mostly below the solution "a", which is explained by the lower amount of the cost associated with the retrofit process. On the other hand, the probability of failure rose suddenly and peaked in the $24^{\text {th }}$ year. It is noticeable that with the retrofit processes "g" and "i", it drops below the probability of failure of the scenario "a". This gives an idea of the viability of the retrofit process and profitability at that stage.

\section{Conclusion}

The works developed a mathematical tool to identify the possibility to recover the structural capacity of a side girder plate of an oil tanker accounting for the probability of failure and cost associated with the retrofit or replacement of the plate.

Four different maintenance actions were considered for the retrofitting process: the replacement of the entire plate, reinforcement by two longitudinal stiffeners, two longitudinal and two transversal stiffeners, a flange on the opening. Twelve scenarios were analysed including four different strategies of accessing the space where the side girder is located to perform the retrofit and replacement are considered: no opening, access from the deck of the vessel, access from the side of the vessel, access from the bottom of the vessel.

The results demonstrated that the more economical and with lower risk solution is the replacement of the entire plate. A better extension of the service life of the retrofitted plate would have been achieved with better coating protection leading to a postpone of the corrosion degradation and reduction of the associated cost during the service life.

The developed mathematical tool is flexible and can be used to identify the most suitable maintenance scenario in recovering the structural capacity of corroded structural components and reducing the associated risk.

\section{Acknowledgement}

This paper reports a work developed in the project" Ship Lifecycle Software Solutions “, (SHIPLYS), which was partially financed by the European Union through the Contract No 690770 - SHIPLYS - H2020MG-2014-2015.

\section{References}

[1] IACS. "Common Structural Rules for Bulk Carriers and Oil Tankers". London: International Association of Classification Societies, 2015.

[2] Moubray, M., 1997, Reliability centred maintenance: Butterworth Heinemann.

[3] Rausand, M., 1998, "Reliability centered maintenance", Reliability Engineering \& System Safety, 60, (2), pp. 121132. https://doi.org/10.1016/S0951-8320(98)83005-6

[4] Jardine, A. and Tsang, A., 2005, Maintenance, Replacement and Reliability, Theory and Applications: Taylor\&Francis. https://doi.org/10.1201/9781420044614

[5] Garbatov, Y. and Guedes Soares, C., 2009, "Predictive reliability of cracked structures based on experimental data", Proceedings of the 13th Congress of International Maritime Association of the Mediterranean (IMAM'09), O. Goren, B. Okan and S. Karakas, editors Istanbul, Turkey, ITU, Faculty of Naval Architecture and Ocean Engineering, Istanbul, Vol. 1, pp. 137-145.

[6] Garbatov, Y. and Soares, C. G., 2009, "Structural maintenance planning based on historical data of corroded deck plates of tankers", Reliability Engineering \& System Safety, 94, (11), pp. 1806-1817. https://doi.org/10.1016/j.ress.2009.05.013

[7] Garbatov, Y. and Guedes Soares, C. "Maintenance Planning for the Decks of Bulk Carriers and Tankers". In: Reliability and risk of structures, infrastructures and engineering systems. H. Furuta, D. M. Frangopol and M. Shinozuka, editors. London, UK: Taylor \& Francis Group, 2010, pp. 3517-3524. 
[8] Jurisic, P., Parunov, J. and Garbatov, Y., 2017, "Aging Effects on Ship Structural Integrity", Brodogradnja, 68, (2), pp. 15-28. https://doi.org/10.21278/brod68202

[9] Rudan, S., Garbatov, Y. and Guedes Soares, C., 2003, "Fatigue damage assessment of side shell longitudinal based on spectral approach", Brodogradnja, 51, pp. 227-234.

[10] Garbatov, Y. and Guedes Soares, C., 1998, "Fatigue Reliability of Maintained Welded Joints in the Side Shell of Tankers", Journal of Offshore Mechanics and Arctic Engineering, 120, (1), pp. 2-14. https://doi.org/10.1115/1.2829516

[11] Guedes Soares, C. and Garbatov, Y. "Reliability of plate elements subjected to compressive loads and accounting for corrosion and repair". In: Structural Safety and Reliability, Vol. 3. N. Shiraishi, M. Shinozuka and Y. K. Wen, editors. Rotterdam, The Netherlands: A. A. Balkema, 1998, pp. 2013-2020.

[12] Guedes Soares, C. and Garbatov, Y., 1998, "Reliability of maintained ship hull girders subjected to corrosion and fatigue", Structural Safety, 20, (3), pp. 201-219. https://doi.org/10.1016/S0167-4730(98)00005-8

[13] Itagaki, H. and Yamamoto, N., 1977, "Bayesian Reliability Analysis and Inspection of Ship Structural Members An Application to the Fatigue Failures of Hold Frames", Proceedings of the International Symposium on Practical Design in Shipbuilding (PRADS'77), Tokyo, pp. 765-772.

[14] Fujita, M., Schall, G. and Rackwitz, R. "Adaptive Reliability Based Inspection Strategies for Structures Subjected to Fatigue". In: Structural Safety \& Reliability. A. H.-S. Ang, M. Shinozuka and G. Schueller, editors.: ASCE, 1989, pp. 1619-1626.

[15] Lotsberg, I. and Kirkemo, A., 1989, "Systematic Method for Planning In-service Inspection of Steel Offshore Structures", Proceedings of the 8th International Conference on Offshore Mechanics and Arctic Engineering (OMAE'89), S. K. Chakrabarti and e. al., editors ASME, Vol. II, pp. 275-284.

[16] Fujimoto, Y. and Swilem, A. M., 1992, "Inspection Strategy for Deterioration Structures Based on Sequential Cost Minimisation Method", Proceedings of the 11th International Conference on Offshore Mechanics and Arctic Engineering (OMAE'92), ASME, Vol. II, pp. 219-226.

[17] Madsen, H. "Stochastic Modeling of Fatigue Crack Growth and Inspection". In: Probabilistic Methods for Structural Design. C. Guedes Soares, editor. Dordrecht: Kluwer Academic Publisher, 1997, pp. 59-84. https://doi.org/10.1007/978-94-011-5614-1_4

[18] Faber, M. H., Kroon, I. B. and Sorensen, J. D., 1996, "Sensitivities in structural maintenance planning", Reliability Engineering \& System Safety, 51, (3), pp. 317-329. https://doi.org/10.1016/0951-8320(95)00107-7

[19] Garbatov, Y. and Soares, C. G., 2001, "Cost and reliability based strategies for fatigue maintenance planning of floating structures", Reliability Engineering \& System Safety, 73, (3), pp. 293-301. https://doi.org/10.1016/S09518320(01)00059-X

[20] Garbatov, Y., Guedes Soares, C. and Wang, G., 2007, "Nonlinear time-dependent corrosion wastage of deck plates of ballast and cargo tanks of tankers", Journal of Offshore Mechanics and Arctic Engineering-Transactions of the ASME, 129, (1), pp. 48-55. https://doi.org/10.1115/1.2426987

[21] Papanikolaou, A. D., Guedes Soares, C., Jasionowski, A., Jensen, J. J., McGeorge, D., Poylio, E. and Vassalos, D., 2009, Risk-Based Ship Design, Springer.

[22] Skjong, R., Vanem, E. and Endersen, Ø. "Risk evaluation criteria, SAFEDOR". In: report D452, 2005.

[23] Guia, J., Teixeira, A. P. and Guedes Soares, C. "Sensitivity analysis on the optimum hull girder safety level of a Suezmax tanker". In: Maritime Technology and Engineering 3. C. Guedes Soares and Santos T. A., editors. London, UK: Taylor \& Francis Group, 2016, pp. 823-830. https://doi.org/10.1201/b21890-108

[24] Garbatov, Y., Sisci, F. and Ventura, M., 2018, "Risk-based framework for ship and structural design accounting for maintenance planning", Ocean Engineering, 166, pp. 12-25. https://doi.org/10.1016/j.oceaneng.2018.07.058

[25] Caridis, P., 2001, Inspection, Repair and Maintenance of Ship Structures: Wetherby.

[26] Garbatov, Y., Ventura, M., Guedes Soares, C., Georgiev, P., Koch, T. and Atanasova, I. "Framework for conceptual ship design accounting for risk-based life cycle assessment". In: Maritime Transportation and Harvesting of Sea Resources. C. Guedes Soares and A. Teixeira, editors. London: Taylor \& Francis Group, 2018, pp. 921-931.

[27] Garbatov, Y. and Sisci, F. "Sensitivity analysis of risk-based conceptual ship design". In: Progress in Maritime Technology and Engineering. C. Guedes Soares and T. A. Santos, editors. London: Taylor \& Francis Group, 2018, pp. 499-510. https://doi.org/10.1201/9780429505294-58

[28] Chichi, D. and Garbatov, Y., 2018, "Reinforcement of Ageing Ship Structures", International Journal of Maritime Engineering, 160, (Part A3), pp. A257-A266.

[29] Shanmugam, N. E., Thevendran, V. and Tan, Y. H., 1999, "Design Formula for Axially Compressed Perforated Plates", Thin-Walled Structures, 34, pp. 1-20. https://doi.org/10.1016/S0263-8231(98)00052-4

[30] Paik, J. K., Hughes, F. and Mansour, A. E., 2001, "Advanced Closed-Form Ultimate Strength Formulation for Ships", Journal of Ship Research, 45, (2), pp. 111-132.

[31] Kim, U. N., Choe, I. H. and Paik, J. K., 2009, "Buckling and Ultimate Strength of Perforated Plate Panels subject to Axial Compression: Experimental and Numerical Investigations with Design Formulations", Ships and Offshore Structures, 4, (4), pp. 337-361. https://doi.org/10.1080/17445300902990606 
[32] Kim, D. K., Kim, S. J., Kim, H. B., Zhang, X. M., Li, C. G. and Paik, J. K., 2015, "Ultimate strength performance of bulk carriers with various corrosion additions", Ships and Offshore Structures, 10, (1), pp. 59-78. https://doi.org/10.1080/17445302.2014.883957

[33] Garbatov, Y., Tekgoz, M. and Soares, C. G., 2016, "Experimental and numerical strength assessment of stiffened plates subjected to severe non-uniform corrosion degradation and compressive load", Ships and Offshore Structures, 12, (4), pp. 461-473. https://doi.org/10.1080/17445302.2016.1173807

[34] Saad-Eldeen, S., Garbatov, Y. and Soares, C. G., 2016, "Experimental investigation on the residual strength of thin steel plates with a central elliptic opening and locked cracks", Ocean Engineering, 115, pp. 19-29. https://doi.org/10.1016/j.oceaneng.2016.01.030

[35] Saad-Eldeen, S., Garbatov, Y. and Guedes Soares, C. "Ultimate bending moment capacity of a single hull structure with multiple large openings on side shell ". In: Maritime Technology and Engineering 3. C. Guedes Soares and T. Santos, editors. London: Taylor \& Francis Group,, 2016, pp. 531-538. https://doi.org/10.1201/b21890-70

[36] Saad-Eldeen, S., Garbatov, Y. and Soares, C. G., 2016, "Experimental strength analysis of steel plates with a large circular opening accounting for corrosion degradation and cracks subjected to compressive load along the short edges", Marine Structures, 48, pp. 52-67. https://doi.org/10.1016/j.marstruc.2016.05.001

[37] Saad-Eldeen, S., Garbatov, Y. and Guedes Soares, C. "FE model calibration and validation of a tested plate with an opening under compressive load". In: Progress in the Analysis and Design of Marine Structures. C. Guedes Soares and C. Garbatov, editors. London: Taylor \& Francis Group, 2017, pp. $305-312$. https://doi.org/10.1201/9781315157368-40

[38] Guedes Soares, C. and Garbatov, Y., 1999, "Reliability of maintained, corrosion protected plates subjected to nonlinear corrosion and compressive loads", Marine Structures, 12, (6), pp. 425-445. https://doi.org/10.1016/S0951$\underline{8339(99) 00028-3}$

[39] Zayed, A., Garbatov, Y. and Soares, C. G., 2018, "Corrosion degradation of ship hull steel plates accounting for local environmental conditions", Ocean Engineering, 163, pp. 299-306. https://doi.org/10.1016/j.oceaneng.2018.05.047

[40] Cantoni, W., Marseguerra, M. and Zio, E., 2000, "Genetic algorithms and Monte Carlo simulation for optimal plant design", Reliability Engineering \& System Safety, 68, (1), pp. 29-38. https://doi.org/10.1016/S0951$\underline{\text { 8320(99)00080-0 }}$

[41] ANSYS, 2009, Online Manuals, Release 11.

[42] Guedes Soares, C., Dogliani, M., Ostergaard, C., Parmentier, G. and Pedersen, P. T., 1996, "Reliability-Based Ship Structural Design", Transactions of the Society of Naval Architects and Marine Engineers (SNAME), 104, pp. 359-389.

[43] Guedes Soares, C. and Moan, T., 1988, "Statistical Analysis of Still-Water Load. Effects in Ship Structures", Transactions of the Society of Naval Architects and Marine Engineers (SNAME), 96, pp. 129-156.

[44] Guedes Soares, C. and Moan, T., 1991, "Model Uncertainty in the Long-term Distribution of Wave-induced Bending Moment for Fatigue Design of Ship Structure", Marine Structures, 4, (4), pp. 295-315. https://doi.org/10.1016/0951-8339(91)90008-Y

[45] Hasofer, A. M. and Lind, N. C., 1974, "An exact and invariant first-order reliability format", Journal of Engineering Mechanics Division, ASCE, 100, pp. 111-121.

[46] COMREL. 2017.

[47] Hellenic. "Low Newbuilding Prices Start to Lure in More Ship Owners". In: HELLENIC SHIPPING NEWS, 2017.

[48] Sørgard, E., Lehmann, M., Kristoffersen, M., Driver, W., Lyridis, D. and Anaxgorou, P. "Data on consequences following ship accidents". In: Safety of shipping in coastal waters (SAFECO II), Vol. WP III.3, D22b: DNV, 1999.

[49] INDEXMUNDI. "Crude Oil monthly price". https://www.indexmundi.com/commodities/?commodity=crude-oil, 2018.

[50] Horte, T., Wang, W. and White, N. "Calibration of the hull girder ultimate capacity criterion for double hull tankers". In: Proceedings of the 10th International Symposium on Practical Design of Ships and other Floating Structures (PRADS), Houston, USA, 2007, pp. 235-246.

Submitted: 26.09.2018. Davide Chichì, davide.chichi@centec.tecnico.ulisboa.pt Yordan Garbatov, yordan.garbatov@tecnico.ulisboa.pt

Accepted: $\quad 23.04 .2019$.

Centre for Marine Technology and Ocean Engineering (CENTEC), Instituto Superior Técnico, Universidade de Lisboa, Lisbon, Portugal 